\title{
The behaviour and ecology of the zebrafish, Danio rerio
}

Rowena Spence $^{1^{*}}$, Gabriele Gerlach ${ }^{2}$, Christian Lawrence ${ }^{3}$ and Carl Smith ${ }^{1}$

${ }^{1}$ Department of Biology, University of Leicester, University Road, Leicester, LE1

$7 R H, U K$.

${ }^{2}$ Marine Biological Laboratory, 7 MBL Street, Woods Hole, MA 02543, USA.

${ }^{3}$ Karp Family Research Laboratories 06-004B, Brigham and Women's Hospital, One Blackfan Circle, Boston MA 02115, USA.

\section{ABSTRACT}

The zebrafish is an important model organism in developmental genetics, neurophysiology and biomedicine, but little is known about its natural ecology and behaviour. It is a small, shoaling cyprinid, native to the flood-plains of the Indian subcontinent, where it is found in shallow, slow-flowing waters. Zebrafish are group spawners and egg scatterers, although females are choosy with respect to sites for oviposition and males defend territories around such sites. Laboratory studies of zebrafish behaviour have encompassed shoaling, foraging, reproduction, sensory perception and learning. These studies are reviewed in relation to the suitability of the zebrafish as a model for studies on cognition and learning, development, behavioural and evolutionary ecology, and behavioural genetics.

Key words: model organism, zebrafish behaviour, zebrafish ecology, wild zebrafish. 
CONTENTS

I. Introduction 4

(1) The zebrafish as a model organism 4

(2) Scope of the review 6

II. Taxonomy

$\begin{array}{ll}\text { (1) Taxonomic status } & 7\end{array}$

(2) Appearance and morphology $\quad 9$

(3) Domestic aquarium strains 10

(4) Pigment patterns in Danio spp. 10

III. Ecology 11

(1) Distribution and habitat 11

(2) Diet 13

(3) Growth and mortality 14

(4) Assemblage 16

(5) Predators 16

(6) Parasites 18

$\begin{array}{ll}\text { IV. Reproductive behaviour } & 19\end{array}$

(1) Spawning cycle $\quad 19$

(2) Mating behaviour $\quad 22$

$\begin{array}{ll}\text { (3) Mate choice } & 25\end{array}$

(4) Oviposition choice $\quad 26$

$\begin{array}{ll}\text { V. Social behaviour } & 27\end{array}$

(1) Shoaling preferences $\quad 27$

(2) Aggression and dominance $\quad 29$

(3) Exploratory behaviour 31

VI. Learning and receiver bias 33

VII. Genetic basis of behaviour $\quad 37$

VIII. Research priorities $\quad 42$

(1) Field-based studies $\quad 42$

(2) Behavioural studies $\quad 43$

(3) Husbandry and welfare $\quad 44$

$\begin{array}{ll}X . & \text { Conclusions }\end{array}$

$\begin{array}{ll}\text { XI. Acknowledgements } & 50\end{array}$

$\begin{array}{ll}\text { XII. References } & 50\end{array}$ 


\section{INTRODUCTION}

\section{(1) The zebrafish as a model organism}

The zebrafish, Danio rerio (Hamilton), is one of the most important vertebrate model organisms in genetics, developmental biology, neurophysiology and biomedicine (Vascotto, Beckham \& Kelly, 1997; Grunwald \& Eisen, 2002; Rubinstein, 2003; Amsterdam \& Hopkins, 2006). It has a number of attributes that make it particularly tractable to experimental manipulation. It is a small, robust fish, so large numbers can be kept easily and cheaply in the laboratory, where it breeds all year round. Females can spawn every 2-3 days and a single clutch may contain several hundred eggs. Generation time is short, typically 3-4 months, making it suitable for selection experiments. Zebrafish eggs are large relative to other fish, $(0.7 \mathrm{~mm}$ in diameter at fertilisation) and optically transparent, the yolk being sequestered into a separate cell. Furthermore, fertilisation is external so live embryos are accessible to manipulation and can be monitored through all developmental stages under a dissecting microscope (Kimmel et al., 1995). Development is rapid, with precursors to all major organs developing within $36 \mathrm{~h}$ and larvae displaying food seeking and active avoidance behaviours within five days post fertilisation, i.e. 2-3 days after hatching (Kimmel et al., 1995).

A popular aquarium species, the zebrafish has been used in developmental biology for many years (e.g. Creaser, 1934). Its current prominence as a model organism stems from the work of Streisinger (1981), who pioneered its use to apply molecular genetics to the study of vertebrate embryology, and Kimmel (1989, 1993; Kimmel et al., 1990), who published detailed descriptions of cell differentiation and nervous system organisation (for review see Grunwald \& Eisen, 2002). The zebrafish was the subject of the first large-scale random mutagenesis screens to be conducted in a vertebrate (Granato \& Nüsslein-Volhard, 1996). These screens, conducted in 1996 in Boston (Driever et al., 1996) and Tübingen (Haffter et al., 1996a), generated over 4,000 mutations and led to the identification of over 400 genes controlling vertebrate development. Since then there have been numerous technological advances (for review see Postlethwait \& Talbot, 1997; Amsterdam et al., 1999; Patton \& Zon, 2001; Golling et al. 2002; Udvadia \& Linney, 2003; Chen \& Ekker, 2004; Guo 2004; Eggert \& Mitchison, 2006; Sood et al., 2006), culminating in the zebrafish genome project, based at the Sanger Institute in Cambridge, which began in 2001 and will shortly be completed (www.sanger.ac.uk). The zebrafish is increasingly important in biomedical research (Dooley \& Zon, 2000; Shin \& Fishman, 2002), particularly as a model of human disease (Berghmans et al., 2005; Guyon et al., 2006) and for the screening of therapeutic drugs (Rubinstein, 2003, 2006). Its strength as a model organism is that as a vertebrate it is more comparable to humans than invertebrate model species such as Drosophila (Postlethwait et al., 1998; Barbazuk et al., 2000), while being more tractable to genetic and embryological manipulation than mammalian model species such as mice, in which such procedures are both more complicated and costly.

Over 400 labs worldwide now routinely use the zebrafish in fundamental and applied research (www.zfin.org) and there is an increasing interest in its use as a model for understanding the genetic basis of behaviour (Gerlai, 2003; Guo, 2004; Miklósi \& Andrew, 2006). Despite this interest, it has attracted little attention from the behavioural ecology community, possibly because little is known about its natural ecology and few studies have been conducted on wild populations. Most laboratory lines of zebrafish are the product of many generations in captivity, which is likely to have resulted in selection for reproductive capacity, while relaxing selection for other traits, such as predator avoidance (Robison \& Rowland, 2005; Wright et al., 2006a). 
Thus, it is not clear in what respects and to what extent domesticated strains may differ from wild fish, nor how much inter-population variation exists in nature. The last comprehensive review of the biology of the zebrafish was by Laale (1977), which focused on physiology. The purpose of this paper is to review the current state of knowledge of the ecology and behaviour of the zebrafish. We use the term behaviour, in this review, not in the sense of a simple reflexive response to stimuli but rather for complex patterns of behaviour such as those involved in social and reproductive behaviour.

\section{(2) Scope of the review}

We begin with a summary of the taxonomic status of the zebrafish, which has recently undergone revision, together with a brief description of its external appearance, and a summary of the main laboratory lines currently used in research. We then review what is known of its natural ecology, including distribution, habitat, natural diet, growth and mortality, assemblage, predators and parasites. Growth and mortality in both wild and domesticated zebrafish are compared although we do not attempt to review zebrafish development, this subject having been extensively dealt with elsewhere (Barinaga, 1990, 1994; Detrich, Westerfield \& Zon, 1999; Kimmel, 1989; Kimmel et al., 1990). The next section focuses on zebrafish reproductive ecology, including spawning behaviour, which is largely known only from studies on domesticated strains although some information is available on wild fish. The majority of behavioural studies on zebrafish are concerned with their aggregation and shoaling; these are reviewed in the next section. We then review what is known about zebrafish cognitive behaviour, including learning, innate biases and sensory biology. While zebrafish genetics is also outside the scope of this review, the next section reviews the growing number of studies that have focused on zebrafish as a potential model for behavioural genetics, and discusses relevant technical issues. We conclude by suggesting potential future directions for research using the zebrafish as a behavioural model.

\section{TAXONOMY}

\section{(1) Taxonomic status}

The zebrafish belongs to the family of freshwater fishes Cyprinidae, the most species rich vertebrate family (Nelson, 1994). There are currently approximately 44 danionin species (Fang, 2001), distributed throughout South and southeast Asia, their highest species diversity in north-eastern India, Bangladesh and Myanmar (Barman, 1991). The name Danio derives from the Bengali name "dhani”, meaning "of the rice field" (Talwar \& Jhingran, 1991). Danios are included in the subfamily Rasborinae (Howes, 1991). They are characterised by small size ( $<120 \mathrm{~mm}$ total length), the presence of a 'danionin notch', in the ventromedial margin of the dentary, and a distinctive colour pattern based on alternating dark and light horizontal stripes, which may be broken up into blotches or bars.

Danio rerio was first described by Francis Hamilton, a surgeon with the British East India company, stationed principally in West Bengal at the beginning of the $19^{\text {th }}$ Century. He published An Account of the Fishes Found in the River Ganges and its Branches in 1822 that included ten Danio species. D. rerio was later assigned to the subgenus Brachydanio, together with the other small Danio species with short dorsal fins and a reduced lateral line, Danio being reserved for the larger species of the group (Weber \& de Beaufort, 1916). Danio and Brachydanio were synonymised by Barman (1991), as there were no diagnostic characters that reliably separated the two 
groups. The first molecular phylogeny of the group was produced by Meyer et al. (1993; 1995) based on $16 \mathrm{~S}$ and $12 \mathrm{~S}$ mitochondrial DNA for nine species. This analysis showed that Danio was monophyletic with two subclades that were either deep-bodied or slender-bodied. Subsequent molecular studies (McClure, 1999; Parichy \& Johnson, 200; Quigley et al. 2004, 2005) supported this distinction, as did a combined molecular and morphological study by Sanger \& McCune (2002). Moreover, Parichy \& Johnson (2001) showed that hybrid viability and fertility among Danio species largely corresponded to the relationships inferred from molecular data.

However, a more complete phylogeny based on morphological analysis proposed that Danio was paraphyletic, the slender-bodied clade being more closely related to Esomus than to the deep-bodied clade (Fang, 2003). This study included 13 Danio species together with an additional eight closely related genera, and was based on 38 morphological characters. The deep-bodied clade has now been assigned the distinct generic name of Devario, and includes most of the striped and barred danios (currently 35 valid species), with Danio sensu stricto, (including D. rerio) restricted to nine species (Fang, 2003). The two genera (Devario and Danio) cannot be reliably distinguished on the basis of proportional measurements alone, as there is considerable intraspecies variation, mature females typically being deeper bodied than males or juveniles. Although Devario tend to be larger, one of the large species, Danio dangila, is included in Danio (Fang, 2001; Parichy \& Johnson, 2001; Quigley et al. 2004, 2005). However, the two genera are ecologically quite distinct, Devario spp. occurring in hill streams with clear running water, while Danio spp. are confined to lowland areas, typically inhabiting slow-flowing, turbid rivers and pools (Fang, 2001).

\section{(2) Appearance and morphology}

Danio rerio rarely exceeds $40 \mathrm{~mm}$ Standard Length (from the tip of the snout to the origin of the caudal fin (SL). Its body shape is fusiform and laterally compressed, with a terminal oblique mouth directed upwards. The lower jaw protrudes further than the upper and the eyes are central and not visible from above. The diagnostic features for the species are an incomplete lateral line extending to the pelvic fin base, two pairs of barbels and five to seven dark blue longitudinal stripes extending from behind the operculum into the caudal fin (Barman, 1991). The anal fin is similarly striped, while the dorsal fin has dark blue upper edge, bordered with white. The colour pattern comprises three types of pigment cell, dark blue melanophores, gold xanthophores and iridescent iridophores (Parichy, 2006a, b). Developmentally, two stripes first form centrally with subsequent stripes being added sequentially above and below (McClure, 1999). As with many teleosts, the melanophores can be concentrated or dispersed in response to stimuli, which appear to function both for camouflage, melanophores aggregating and dispersing in response to light intensity (Guo, 2004) and signalling, fish typically darkening during aggressive display (Gerlai, 2003; Larson, O’Malley \& Melloni, 2006). Males and females are of similar colouration, although males tend to have larger anal fins with more yellow colouration (Laale, 1977; Schilling, 2002). The sex of juveniles cannot be reliably distinguished without dissection and while gravid females have a more rounded body shape, the most reliable diagnostic feature is the presence of a small genital papilla in front of the anal fin origin (Laale, 1977). 


\section{(3) Domestic aquarium strains}

Zebrafish used for mutagenesis and screening are from lines bred in laboratories for many generations in order to maintain a stable genetic background. They are also "cleaned up"; i.e. bred selectively to remove embryonic lethal mutations. The main currently recognised wild-type lines from the Zebrafish International Resource Center are summarised in Table 1. For details of mutant lines see http://zfin.org.

The "leopard" danio, which displays a spotted colour pattern instead of stripes, was originally thought to be a separate species, described as Brachydanio frankei (Meinken, 1963). However, neither molecular nor morphological analyses have differentiated between the two (Fang 1998; Meyer et al., 1993) while hybrids were shown to produce fertile progeny (Petrovicky, 1966). The leopard danio is now known to be a spontaneous mutation of the wild-type D. rerio colour pattern (Haffter et al., 1996b), with homozygotes displaying a spotted pattern, while heterozygotes have a disrupted stripe pattern (Watanabe et al., 2006). Leopard danio mutants are primarily bred for the aquarium trade but also occur in nature (R. Spence, pers. obs.). Another aquarium variant is the "longfin" $D$. rerio, which is a dominant mutation resulting in elongated fins (Plaut, 2000). The commonly used wild-type strain, TL or Tübingen Long-fin displays both the "leopard" and "longfin" mutations (www.zfin.org).

\section{(4) Pigment patterns in Danio spp.}

Comparison of pigment patterns among Danio species has provided insights into their evolutionary relationships. Larval danios of different species exhibit an identical pigment pattern, which only differentiates into the adult pattern in about the third week of development (McClure, 1999). Interestingly, several D. rerio pigment pattern mutations resemble other Danio species (Parichy \& Johnson, 2001). This remarkable concurrence in appearance raises the possibility that the alleles expressed by zebrafish colour mutants are the same as those expressed in related Danio species. Consequently, these alleles may have played a role in colour pattern diversification among species (Parichy \& Johnson, 2001).

A spectacular array of adult pigment pattern mutants have been identified for zebrafish (Haffter et al., 1996b; Kelsh et al., 1996). Many mutant colour patterns can be attributed to a single locus, and several pigment genes have been identified at the molecular level (Lister et al., 1999; Kawakami et al., 2000; Lamason et al., 2005). In a study of colour pattern inheritance, Parichy \& Johnson (2001) showed that hybrids between zebrafish and four closely related Danio species all expressed pigment patterns resembling that of wild-type zebrafish. These findings imply that stripes may be ancestral in Danio spp. Thus the zebrafish may serve as a useful model for studying the genetic and developmental basis of colour pattern evolution as a mechanism for speciation (Parichy 2006a, b).

\section{ECOLOGY}

\section{(1) Distribution and habitat}

The natural range of the zebrafish is centred around the Ganges and Brahmaputra river basins in north-eastern India, Bangladesh and Nepal although in the past specimens have also been collected in the Indus, Cauvery, Pennar, Godavari and Mahanadi river basins (Fig. 1). In addition, it has been reported as occurring in the Krishna river basin (Talwar \& Jhingran, 1991) and in the states of Rajasthan, Gujarat and Andra Pradesh (river basins draining into the Arabian Sea) as well as northern Myanmar and Sri Lanka, although no location details are given (Barman, 1991). The 
reliability of some of the earlier records is questionable; either no specimens appear to have been collected (as in the case of records for Sri Lanka), or the specimen has been reclassified (as in the case of at least one species from Myanmar, now designated Danio kyathit, Fang, 1998). Database records for this species should not be considered as complete (see www.fishbase.org; Spence 2006). However, on the basis of confirmed occurrences, the zebrafish may be widely distributed over the Indian subcontinent; it may be overlooked in surveys on account of its small size and the fact that it has no value as a food fish, even to subsistence fishermen.

The Indian subcontinent has a monsoon climate with wide seasonal variation in the extent of freshwater habitats. Some of the major river systems, such as the Ganges, run through low-lying areas that flood extensively during the monsoon months. The floodplains are characterised by oxbow lakes and blind channels, which may have seasonal connections to the main river. In addition, these regions contain extensive areas of man-made lakes, ponds and irrigation channels, constructed for fish and rice cultivation. There is a wide range of temperatures within the natural range of zebrafish, from as low as $6{ }^{\circ} \mathrm{C}$ in winter to over $38^{\circ} \mathrm{C}$ in summer.

Zebrafish have typically been described as inhabiting slow-moving or standing water bodies, the edges of streams and ditches, particularly adjacent to rice-fields (Sterba, 1962, Talwar \& Jhingran, 1991; Jayaram, 1999). However, they are also reported as inhabiting rivers and hill streams (Daniels, 2002). This inconsistency in habitat preference probably results from the taxonomic confusion between Danio and Devario (Fang, 2001). Three surveys have systematically described their habitat preferences; McClure, McIntyre \& McCune (2006) captured zebrafish in three sites in the Ganges drainage in India, Spence et al., (2006a) captured them in nine sites in the Ganges and Brahmaputra drainages in Bangladesh, and Engeszer et al. (2007a) captured them in 14 sites in the Ganges and Brahmaputra drainages in India. In all three studies, zebrafish were found to occur in shallow waterbodies with a visibility to a depth of $\sim 30 \mathrm{~cm}$, frequently in unshaded locations with aquatic vegetation and a silty substrate.

Zebrafish appear to be a floodplain rather than a true riverine species. They are most commonly encountered in shallow ponds and standing water bodies, often connected to rice cultivation. This association with rice cultivation may relate to the use of fertilisers that may promote the growth of zooplankton, a major component of the zebrafish diet (Spence et al., 2007a). Rice paddies and shallow seasonal waters are also likely to be free from large predatory fishes. Spence et al. (2006b) found no zebrafish either in rivers or temporary creeks that opened during the monsoon season. Where zebrafish are found in streams and rivers, these typically have a low flow regime and zebrafish were most often encountered at the margins (McClure et al., 2006; Engeszer et al. 2007a.). Behavioural observations of their vertical distribution indicated that they occupy the whole of the water column and occur as frequently in open water as amongst aquatic vegetation (Spence et al., 2006b).

\section{(2) Diet}

The zebrafish is omnivorous, its natural diet consists primarily of zooplankton and insects, although phytoplankton, filamentous algae and vascular plant material, spores and invertebrate eggs, fish scales, arachnids, detritus, sand and mud have also been reported from gut content analysis (Dutta, 1993; McClure et al., 2006; Spence et al., 2007a). The majority of insects identified in these studies were aquatic species, or aquatic larval forms of terrestrial species, particularly dipterans, and it has been suggested that the zebrafish may have some value in mosquito control (Dutta, 1993). 
The high proportion of planktonic items in their diet indicates that zebrafish feed chiefly in the water column. However, terrestrial insects and arachnids are also consumed, suggesting surface feeding, while the presence of inorganic elements and detritus suggest they also feed from the substrate. In a study based on sampling over 12 months, dietary composition appeared to differ significantly among months although no clear seasonal pattern was apparent (Spence et al., 2007a). Additional data are required to determine the extent to which food items in the gut of zebrafish reflect selectivity on the part of the fish as opposed to seasonal availability of different prey.

\section{(3) Growth and mortality}

Zebrafish growth rate is most rapid during the first three months following hatching, after which it starts to decrease, approaching zero by about 18 months (Spence et al., 2007a). Growth rates of domesticated strains in the laboratory have been reported as higher than those for wild fish. Eaton and Farley (1974a) reported an annual growth rate of $183 \mathrm{~mm} \mathrm{y}^{-1}$ during the first 45 days of development, compared to $72 \mathrm{~mm} \mathrm{y}^{-1}$ during the first two months in nature (Spence et al., 2007a). This difference in growth rates could result from inadvertent selection for rapid growth or as a consequence of higher food intake in captivity. The latter explanation is more likely, as $F_{2}$ offspring of wild-caught fish grow at an equivalent rate to domesticated strains under controlled conditions in the laboratory (C. Smith \& R. Spence, unpublished data). Domesticated strains have also been reported to achieve a larger body size than some populations of wild fish (Wright et al., 2006a). A length-frequency analysis based on sampling over 12 months from a lake population in Bangladesh showed the mean length of fish to be $25 \mathrm{~mm}$ after one year. The maximum SL observed was $35 \mathrm{~mm}$ (Spence et al., 2007a), which is comparable to the typical range observed in laboratory strains. The size difference may be partly due to genetic factors (Wright et al., 2006a, 2006b), with selection for fast growth and high fecundity among laboratory fish, but it may also reflect rearing conditions; in the laboratory, F1wild fish also achieve $35 \mathrm{~mm}$ SL after 18 months (R. Spence \& C. Smith, unpublished data). Females tend to be larger than males both in domesticated and wild populations (Eaton \& Farley, 1974a, 1974b; Spence et al., 2007a). The extent of variation in growth rates and body size among wild populations is unknown.

The zebrafish appears to be primarily an annual species in nature, the spawning season commencing just before the onset of the monsoon (Spence et al., 2007a). Length-frequency analysis showed two distinct age classes during the summer months, representing reproductively mature $1+$ year fish and a cohort of $0+$ fish. Thus, the main period of rapid growth takes place during the monsoon months (JuneSeptember), a period of high temperatures (up to $34^{\circ} \mathrm{C}$ ) and food availability (Talling \& Lemoalle, 1998).

Gerhard et al. (2002) reported a mean life span of domesticated zebrafish of 42 months, with the oldest individual surviving for 66 months. However, instances of spinal curvature, a phenotype caused by muscle degeneration and commonly associated with senescence (Gerhard et al., 2002; Kishi et al., 2003), become apparent in domesticated and wild zebrafish after their second year in captivity (R. Spence, pers. obs.). Spinal curvature was not observed in a wild population (Spence et al., 2007a) and it is likely that fish die in natural populations before this condition develops. 


\section{(4) Assemblage}

Where zebrafish are found, they tend to be among the most abundant species (McClure et al., 2006; Spence et al., 2006a; Engeszer et al. 2007a). Spence et al. (2006a) captured a total of 25 species from nine families that co-occurred with zebrafish over their range in Bangladesh, while Engeszer et al. (2007a) captured 36 species from 16 families. These were primarily small $(<25 \mathrm{~cm}$ total length) indigenous species. Such species represent potential competitors of zebrafish. Zebrafish were often observed shoaling together with the flying barb Esomus danricus (Hamilton), another abundant cyprinid of similar size and appearance that is closely related to Danio (Fang, 2003). Other potential competitors are Puntius spp. and Aplocheilus panchax (Hamilton).

The other danionin species found with zebrafish were Danio dangila (Hamilton), D. meghalayensis (Sen \& Dey), Devario devario (Hamilton), Devario assamensis (Barman) and D. aequipinnatus (McClelland). McClure et al. (2006) reported significant differences in the characteristic temperature, $\mathrm{pH}$ and current speed of the habitats in which different danionin species occurred; the Devario species typically inhabited faster flowing water whereas zebrafish were captured in the margins of streams and rivers. This corresponds with Fang's (2001) finding that the two genera occupy different microhabitats.

\section{(5) Predators}

The most common predatory taxa captured with zebrafish were snakeheads, Channa spp., and the freshwater garfish, Xenentodon cancila (Hamilton) (Engeszer et al. 2007; Spence et al. 2006a), although sampling protocols may have failed to capture other potential predators such as nocturnal catfishes. Engeszer et al. (2007a) additionally captured the catfish Mystus bleekeri (Day) and the knifefish, Notopterus notopterus (Pallas). Mastacembelids, which also co-occur with zebrafish, are oophagous and may be predators of zebrafish eggs and embryos, while odonate larvae may be predators of larval and juvenile zebrafish (Engeszer et al. 2007a). Adult zebrafish are also predators of zebrafish eggs and larvae. Avian predators such as the Indian pond heron, Ardeola grayii (Sykes) and the common kingfisher, Alcedo atthis L., are also ubiquitous in the floodplains of the Indian subcontinent and may feed on D. rerio.

Laboratory studies have shown that zebrafish display fright reactions in response to both visual and olfactory cues associated with predators. Dill (1974a, 1974b) used both living (largemouth bass, Micropterus salmoides (Lacepède) and model predators to investigate zebrafish escape responses. The distance at which the response was elicited depended on the predator's size and its approach velocity. Reactive distance did not differ significantly between living and model predators, although escape velocity was higher with living predators. Over repeated trials on successive days, zebrafish responded earlier and flight distance increased. No decline in response was detected when zebrafish were retested after a 10-day break. This effect may be an example of secondary reinforcement; as the predator's approach was associated with a negative experience, the fish began to respond before the initial threshold was reached.

In common with other ostariophysian fishes, zebrafish show alarm behaviours in response to a pheromone that is released as a result of injury to the epidermal cells (Pfeiffer, 1974; Wisenden, Vollbrecht \& Brown, 2004). Alarm behaviours include an increase in shoal cohesion and either agitated swimming or freezing on the substrate, a decrease in feeding rate and increase in aggression. These behaviours have been 
interpreted as having an anti-predator function. Rehnberg \& Smith (1988) demonstrated that isolated zebrafish showed an alarm response to water containing alarm substance, so the response is independent of the presence of conspecifics.

\section{(6) Parasites}

Little is known about the natural parasite fauna of zebrafish, or the role parasites play in their behaviour and ecology. In a preliminary study conducted in Bangladesh, based on an analysis of 120 specimens from seven sites, infection by 20 species of metazoan parasites and three protozoans was observed (R. Spence \& C. Smith, unpublished data). The majority of parasites were larval stage digeneans, cestodes and acanthocephalans, while ectoparasite infection was rare. Infection by Acanthostomum sp., Centrocestus sp. and one diplostomoid species was observed in all the locations sampled, with $100 \%$ prevalence being observed for the metacercariae of Acanthostomum sp. in one site and Centrocestus sp. in two sites.

In laboratory stocks, infection by the microsporidian Pseudoloma neurophilia is common (Spitzbergen \& Kent, 2003). It infects the central nervous system, cranial and spinal nerves, and skeletal muscle of zebrafish, causing emaciation, ataxia and spinal malformations. It is not clear whether vertical transmission of this parasite can occur in zebrafish. Captive zebrafish have also been subject to infection by the nematode Pseudocapillaria tomentosa, which infects the gut; symptoms include inflammation, emaciation and intestinal carcinomas (Kent et al., 2002). P. tomentosa can be transmitted directly and infects entire laboratory colonies. There are many possible explanations for this phenomenon but the finding that nematode infection appears to be rare in nature may indicate that zebrafish have not evolved natural immunity to the effects of parasitism by nematodes.

\section{REPRODUCTIVE BEHAVIOUR}

\section{(1) Spawning cycle}

Much of the scientific literature on zebrafish reproduction has been concerned with how best to maximise the supply of eggs for research (reviewed by Laale, 1977) and,

until recently, almost nothing was known about the reproductive ecology of wild zebrafish. In zebrafish, all gonads initially develop as ovaries, which in males start to differentiate at approximately 5-7 weeks post hatching (10-15 mm TL) through an intersexual stage, finally developing into normal testes by approximately the third month of development (12-17 mm TL), depending on strain and rearing conditions (Devlin \& Nagahama, 2002; Maak \& Segner, 2003). The genetic mechanism of sex determination in zebrafish is unknown. However, there is evidence that food supply or growth rate affects sex determination, faster growing individuals developing as females and slower growing individuals as males (Lawrence, Ebersole \& Kesseli, 2007). Based on samples collected from a population in Bangladesh, sex ratios in nature appear to be 1:1 (Spence et al., 2007a).

In the laboratory, domesticated zebrafish strains breed all year round whereas in nature spawning is more seasonal. However, larger females collected in January (outside the main spawning season) have been found to contain mature ova, indicating that reproduction may not be cued by season, but may instead be dependent on food availability, which is likely to co-vary with season (Spence et al., 2006a). Further, reproductive maturity appears to be related to size rather than age; wild and domesticated zebrafish appear to reach reproductive maturity at similar sizes, despite having different growth rates. Eaton and Farley (1974a) showed that domesticated zebrafish reared at $25.5{ }^{\circ} \mathrm{C}$ reached maturity after 75 days, when females were 24.9 
mm SL and males $23.1 \mathrm{~mm}$. In laboratory conditions, $\mathrm{F}_{1}$ wild zebrafish also reach reproductive maturity at approximately $23 \mathrm{~mm}$ SL (R. Spence, pers. obs.).

Pairs of zebrafish left together continuously spawn at frequent but irregular intervals (Eaton \& Farley, 1974b), and a single female may produce clutches of several hundred eggs in a single spawning. In a study by Spence \& Smith (2006) inter-spawning intervals ranged from 1-6 days, with a mean of 1.5 days, producing clutches ranging from 1 to over 700 eggs, with a mean of 185 ( \pm SD 149). Clutch size correlated positively with both female body size and inter-spawning interval. Eaton \& Farley (1974b) reported that inter-spawning interval increased with age, from a mean of 1.9 days in 12-month old fish to 2.7 days three months later. Clutch size also increased over this period from a mean of 158 to 195. No equivalent data are available for wild zebrafish, but inter-spawning intervals tend to be greater and clutch sizes smaller than domesticated strains (R. Spence, pers. obs.).

Ovulation is dependent on female exposure to male gonadal pheromones; male holding water, testis homogenates and testis fractions containing steroid glucuronides, will induce ovulation but fail to do so in females rendered anosmic by cauterising the nasal epithelium (van den Hurk \& Lambert, 1983; van den Hurk et al., 1987). Eaton \& Farley (1974b) showed that exposure to a male for $7 \mathrm{~h}$ in the afternoon was sufficient to enable eggs to be stripped from females the following morning. However, eggs were never obtained from isolated females more than once in any 5day period after exposure to a male. Thus it appears that all mature ova are released in a single spawning bout (Hisaoka \& Firlitt, 1962; Eaton \& Farley, 1974b).

The presence of a male is essential for females to spawn eggs. Females kept in isolation or older females can become "eggbound" (Fig. 2a \& b) which can be lethal in severe cases. Dissections of eggbound females showed that a $3 \times 3 \mathrm{~mm}$ plug consisting of necrotic clumped eggs clogging the oviduct which can prevent any further successful spawning (Gerlach unpublished results). Regular exposure to males and spawning dishes can prevent this development. Interestingly, despite the fact that egg production is non-continuous, females exposed to male pheromones for several days prior to spawning produce more eggs, of higher quality, than females isolated for several days (Gerlach, 2006). This effect could be a consequence of the concentration of pheromones to which they are exposed. Bloom \& Perlmutter (1977) showed that both sexes produce pheromones that function as inter- and intra-sexual attractants, and have different effects at different concentrations. For both sexes, the intra-sexual response was elicited at a lower concentration than the inter-sexual response.

Eggs are non-adhesive and demersal, with a diameter of approximately $0.7 \mathrm{~mm}$. They are released directly over the substrate with no preparation of the substrate by either sex and there is no parental care. Eggs become activated on contact with water and even in the absence of sperm, undergo a series of programmed developmental steps. Unfertilised eggs develop a perivitilline space but fail to develop beyond the first few cleavages (Lee, Webb \& Miller, 1999). Hatching takes place between 48-72 $\mathrm{h}$ at $28.5^{\circ} \mathrm{C}$, depending on the thickness of the chorion and the muscular activity of the embryo inside, both of which can vary within a group of embryos (Kimmel et al., 1995). Immediately after hatching the larvae (measuring $\sim 3 \mathrm{~mm}$ ) attach to hard surfaces by means of small secretory cells in the epidermis of the head (Laale, 1977). Attachment at progressively higher levels enables them to reach the surface to which they need to gain access in order to inflate their swim bladders (Goolish \& Okutake 1999). This process occurs from about $72 \mathrm{~h}$ post fertilisation, whereupon swimming, feeding and active avoidance behaviours commence (Kimmel et al., 1995). 


\section{(2) Mating behaviour}

It is well known that spawning in domesticated zebrafish is influenced by photoperiod (Breder \& Rosen, 1966). Zebrafish show a distinct diurnal activity pattern, synchronised with the light/dark and feeding cycles. The first activity peak occurs immediately after illumination with two further peaks in the early afternoon and the last hour of light (Baganz et al., 2005; Plaut, 2000). Spawning activity coincides with the first activity peak and usually commences within the first minute of exposure to light following darkness, continuing for about an hour (Darrow \& Harris, 2004). Field observations have shown that spawning in zebrafish under natural conditions is also largely limited to a short period at dawn (Spence, Ashton \& Smith, 2007). Notably, wild-caught zebrafish held in captivity are more likely than domesticated strains to spawn at times other than first light (R. Spence, pers. obs.). Extended day length may be a contributory factor in the seasonal onset of spawning in nature. It was noted by Breder \& Rosen (1966) that adding a dash of cold water to aquaria could encourage spawning in zebrafish. Thus, it may be that a drop in water temperature or an increase in water level may be additional cues used by zebrafish. In nature, zebrafish spawn during periods of heavy rain (R. Spence, pers. obs.).

Courtship behaviour in zebrafish consists of a male chasing the female rapidly, often nudging her flanks with his snout and attempting to lead her to a spawning site (see below), swimming around or in front of her in a tight circle, or figure of eight, with his fins raised. If she does not follow, he may alternate between circling the female and swimming back and forth between the female and the spawning site. Once over a spawning site he swims closely alongside the female, spreading his dorsal and caudal fins around her so that their genital pores are aligned, and may oscillate his body at high frequency and low amplitude. This behaviour triggers oviposition in the female and sperm is released simultaneously. This sequence of behaviours is repeated throughout the spawning period, females releasing between 5-20 eggs at a time. Male courtship behaviour is most active in the first 30 minutes and although it continues for about an hour, few females extrude eggs after the first 30 minutes (Darrow \& Harris, 2004). Wild zebrafish display similar courtship and territorial behaviours during spawning as have been described in domesticated strains (Spence et al., 2007b). Under more natural conditions, courtship involves males actively pursuing females, who utilize the whole of the water column, alternately swimming towards the surface and then diving steeply down to the substrate to spawn. Small groups of 3-7 fish usually take part in these chases.

Courtship behaviour in the male is triggered by female pheromones. In a study by van den Hurk \& Lambert (1983) males, but not females, were attracted to ovarian extracts injected into the aquarium. Anosmic males failed to court females while control males only courted females that had ovulated. Further, anosmic males were extremely aggressive, suggesting that ovarian pheromones also inhibit aggression that is common in both sexes during foraging.

Zebrafish typify a basic mating pattern common to many cyprinid fishes; they are group spawners and egg scatterers (Breder \& Rosen, 1966). Females will spawn directly onto a bare substrate, but when provided with an artificial spawning site, such as a plastic box filled with marbles, will preferentially use it for oviposition (Spence \& Smith, 2005). Some male zebrafish are territorial during mating (Spence \& Smith, 2005). Both territorial and non-territorial males show the same courtship behaviour but whereas non-territorial males pursue females, territorial males confine their activities to within a few body lengths of a spawning site and chase other males away when they try to approach. A study by Spence \& Smith (2005) examined the effects 
of manipulating density and sex ratio on the behaviour of these territorial males. Aggression rates increased as a function of density. However, while courtship behaviour increased with density under a female-biased sex ratio, when the sex ratio was male biased courtship rate decreased relative to that observed at low densities. A subsequent microsatellite parentage analysis showed that the reproductive success of territorial males was also density dependent (Spence, Jordan \& Smith, 2006). At low densities territorial males sired significantly more offspring than non-territorial males. However, at high densities territorial males were no more successful than nonterritorials. Thus male zebrafish display two distinct mating tactics, territorial defence and active pursuit of females, the adoption of which is flexible and may be density dependent.

Density can also affect female reproductive success. Spence \& Smith (2005) showed that in their study mean per capita egg production decreased at higher densities. A parentage analysis indicated that this effect was due to females spawning smaller clutches, rather than some females being excluded from spawning (Spence et al., 2006b). There are several possible explanations for reduced female egg production at high densities; increased male-male aggression may interfere with female oviposition attempts and/or competition may arise among females for access to spawning sites. Alternatively, reduced female egg production may arise through pheromonally mediated reproductive suppression. Females exposed to the pheromones of other females for several days prior to spawning have been shown to be significantly less likely to spawn compared to isolated females (Gerlach, 2006). Further, dominant females produce more eggs than subordinates (Gerlach, 2006). In a study on female territoriality conducted in a large $2 \times 2 \mathrm{~m}$ aquarium, Delaney et al. (2002) showed that females avoid the presence and, therefore, also the direct exposure to pheromones of other females. Females significantly preferred to stay with one or several males but not with females. Tested in a T-maze, an increasing concentration of chemical cues from female zebrafish elicited avoidance behaviour in other females (Golubev 1984). Thus, competition among both males and females may play a role in the zebrafish mating system.

\section{(3) Mate choice}

The existence and nature of female mating preferences can be difficult to demonstrate in species where male competition plays a significant part in the mating system; matings are likely to be determined by the dominant male excluding other males rather than females actively choosing mates. There is some evidence that female zebrafish prefer larger males (Pyron, 2003), and body size tends to correlate with dominance in teleost fishes (Wootton, 1998). When female egg production is used as a measure of preference, female zebrafish do appear to prefer some males over others (Spence \& Smith, 2006). However, these preferences do not correlate with male dominance, neither do females correspond in their choice of males (Spence \& Smith, 2006). In view of the role played by pheromones in the reproductive behaviour of both sexes, it is possible that mating preferences may be based on olfactory cues. For instance, female zebrafish prefer the odour of unrelated males to unfamiliar brothers (Gerlach \& Lysiak, 2006). In the zebrafish mating system the two mechanisms of sexual selection, male-male competition and female preference, may operate in opposition. If females do not prefer dominant males, their preferences may undermine the ability of dominant males to monopolise matings. Further, competition among males for mating opportunities may be balanced by similar competition among females (Gerlach, 2006). Indeed, variance in reproductive success among females is 
equivalent to that among males, and consequently the opportunity for sexual selection is weak in zebrafish (Spence et al., 2006b), borne out by the fact that they do not display striking sexual dimorphism.

\section{(4) Ovipostion choice}

Females are choosy with respect to sites for oviposition. In choice tests conducted both with domesticated fish in the laboratory and with wild fish in a field-based mesocosm, females preferred a gravel substrate to silt (Spence et al., 2007b). Territorial males were also observed to defend gravel-substrate spawning sites in preference to silt. This preference appears to relate to spawning site quality; egg survival is enhanced by incubation in a substrate that allows oxygenated water to circulate while protecting them from disturbance and cannibalism. In the laboratory, a preference for vegetation was also observed, although vegetation did not affect survival. Vegetation is thought to be important in the survival of larval zebrafish; they possess attachment organs that may assist them in reaching the surface to inflate their swim bladders (Laale, 1977). In the types of habitat where zebrafish are common, such as floodplain ponds, the substrate is often silty and zebrafish are thought to spawn in shallow vegetated areas that offer protection from predators (Engeszer et al., 2007; Spence et al., 2007b). Thus, there may be competition for access to sites that afford better water circulation as well as protection for eggs and larvae. Choice of oviposition site is one of the few ways in which oviparous species with no parental care can maximize offspring survival. Thus, if females actively choose oviposition sites, males may increase their reproductive success by guarding such sites.

\section{SOCIAL BEHAVIOUR}

\section{(1) Shoaling preferences}

Zebrafish are a shoaling species, a behaviour that appears to be innate; shoaling behaviour commences soon after hatching (Engeszer et al. 2007b) and fish reared in isolation quickly form shoals when placed together (Kerr, 1963). McCann \& Matthews (1974) showed that zebrafish reared in isolation did not discriminate between shoals of conspecifics, pearl danios, Danio albolineatus (Blyth), or guppies, Poecilia reticulata (Peters), suggesting that species identification is learned. McCann \& Carlson (1982) tested this by cross-rearing zebrafish with the closely related unstriped pearl danio. Cross-reared individuals showed a reduced preference for associating with conspecifics. Engeszer, Ryan \& Parichy (2004) showed that preferences for different intraspecific phenotypes are also learned. Wild-type zebrafish cross-reared with with the stripeless pigment mutant nacre preferred the colour pattern of those with which they had been raised, irrespective of their own appearance. Based on a comparison of shoaling preferences among five different danio phenotypes, stripes appear to be a key shoaling cue (Rosenthal \& Ryan, 2005). These studies suggest that species recognition in the zebrafish is mediated by a process of phenotype matching against a template based on early experience. Engeszer et al. (2007b) found that the visual preference of juvenile wild-type zebrafish for like phenotype remained even when their social environment was manipulated by placing individuals in groups of nacre shoalmates for 30 days. However, McCann and Carlson (1982) found that the visual preference of crossreared subjects was eroded after similar manipulation. These observations together suggest that template formation involves both genetic and learned components.

Zebrafish have also been shown to use olfactory cues in both species and kin recognition (Gerlach \& Lysiak, 2006). In a series of odour flume choice tests, juvenile 
zebrafish preferred conspecifics to heterospecifics, unfamiliar kin to non-kin, and familiar to unfamiliar kin. Thus, social preferences in zebrafish may be based on individual recognition as well as phenotype matching. Individual recognition may play a role in zebrafish since this species is known to establish dominance hierarchies (Grant \& Kramer, 1992; Gerlach, 2006; Spence \& Smith, 2006). The mechanism underlying this olfactory recognition is not yet known.

Shoaling decisions in zebrafish are also influenced by shoal size and activity level. In a test of shoaling preferences, Pritchard et al. (2001) showed that individuals generally preferred larger shoals. However, when shoal activity level was manipulated by changing the water temperature, fish preferred the more active shoal, regardless of size. Preferences also appear to differ between the sexes (Rhul \& McRobert, 2005). Male zebrafish preferred to associate with female shoals compared to males but had no preference for shoal size. However, females preferred to associate with the larger shoal, regardless of whether it was composed of males or females. Zebrafish appear to be able to assess the nutritional state of conspecifics; food-deprived individuals preferred to shoal with well-fed conspecifics, and had increased foraging success than when shoaling with other food-deprived individuals (Krause et al., 1999).

Tests of shoaling preference based on visual cues have been conducted between wild-type zebrafish and various aquarium variants: leopard danios (Spence \& Smith, 2007), longfin (Kitevski \& Pyron, 2003) and the transgenic Glofish ${ }^{\mathrm{TM}}$, which are genetically engineered to express red fluorescent proteins (Snesker et al., 2006). No significant preference was detected in any of these tests. However, Gerlach et al. (submitted) showed that inter-individual distance between juvenile zebrafish kept in mixed groups of either albino (lacks melanin), roy (lacks irridophores) and wildtype strains was significantly smaller among individuals of the same strain than of different strains.

\section{(2) Aggression and dominance}

Zebrafish of both sexes can establish dominance hierarchies. Aggressive interactions involve chasing and in some cases biting. Display behaviour involves pairs of fish orienting head to tail with their fins splayed and slowly circling one another while ascending (R. Spence, pers. obs.). This behaviour operates within and between the sexes; its function is not clear but it may be a means of individual recognition that reinforces dominance ranks. Once dominance relationships become established, aggression becomes less intense (Larson et al., 2006). When fish are housed in pairs, the dominant individual often appears darker and utilises the entire aquarium, while subordinates are pale and occupy a smaller area (Larson et al., 2006). Dominance relationships appear to be relatively stable over time, at least over the duration of fiveday experiments (Grant \& Kramer, 1992; Spence \& Smith, 2005). Moreover, males separated for four days have been shown to re-establish identical dominance ranks once reunited (G. Gerlach, unpublished data).

The sex of an individual does not appear to be an important factor in determining its dominance rank (Grant \& Kramer, 1992). The relationship between body size and dominance is unclear, partly because studies often control for size (Grant \& Kramer, 1992; Spence \& Smith, 2005, 2006). However, in studies using fish of different sizes, Hamilton \& Dill (2002) found that size correlated positively with rank, while Basquill \& Grant (1998) found that it was not. Dominance has been demonstrated both during mating behaviour, where males establish territories around spawning sites (Spence \& Smith, 2005) and foraging, where dominant individuals attempt to monopolise a food source (Grant \& Kramer, 1992; Basquill \& Grant, 1998; Hamilton \& Dill, 2002). It is 
not known whether males that are territorial during spawning are also dominant during foraging.

In a study of zebrafish foraging behaviour, Gillis \& Kramer (1987) manipulated fish density and food patch profitability. Zebrafish formed shoals but aggressive interactions took place near feeding sites. The distribution of fish was affected by patch profitability, with more fish being concentrated around the most profitable food patch. However the variability in the distribution between the three patches was greater when fish density was lower. At high densities there were more fish in the least profitable patch and fewer in the most profitable patch than would be predicted by an Ideal Free Distribution model (Fretwell \& Lucas, 1970). Aggressive interference did not fully explain the density-related reduction in foraging efficiency; aggressive interactions increased with patch profitability but decreased at high population densities. Thus, foraging distributions may also be influenced by nonaggressive interactions, while aggressive interactions are ameliorated at high densities.

Aggression and food monopolisation are also influenced by habitat structure. Basquill \& Grant (1998) compared levels of aggression in a vegetated versus a nonvegetated habitat. Aggression and food monopolisation by the dominant fish were lower in the vegetated habitat. This effect could be because the presence of vegetation makes the environment more difficult to defend. An alternative explanation is that a vegetated environment is perceived as safer; dominant fish may be more willing to forage in open habitats where predation risk is higher, while to subordinate fish the perceived benefit of shoaling in a risky habitat may outweigh the cost of reduced foraging efficiency. In order to test these two hypotheses Hamilton \& Dill (2002) compared aggression and resource monopolisation among three habitats, open, vegetated, and unvegetated with overhead cover. When allowed to choose, fish preferred to forage in the covered habitat and there was no effect of vegetation. There was no difference in aggression among habitats, but resource monopolisation was greater in the open "risky" habitat.

Rearing environment may also influence aggression and dominance. Marks et al. (1999) found that fish raised in an hypoxic environment were less aggressive and spent more time in refugia than those reared in a normoxic environment. This result suggests that zebrafish offer a potential model for exploring phenotypic plasticity in behaviour, particularly developmental plasticity.

\section{(3) Exploratory behaviour}

Shoaling behaviour can increase the probability of an individual fish detecting and avoiding predators (Pitcher \& Parrish, 1993). A related behaviour is predator inspection, whereby individual fish leave a shoal briefly to approach a predator. These two traits are known to be at least partly genetically determined in zebrafish. Wright et al. (2003) showed differences in "boldness" (defined as the propensity to approach a novel object, in the shape of a black cylinder suspended in an experimental aquarium) among laboratory raised wild $\left(\mathrm{F}_{2}\right)$ zebrafish from four different populations. An intra-population study indicated a genetic component to shoaling tendency (the time an individual fish spent associating with a stimulus shoal), although there was no equivalent interpopulation difference. In a further study, Wright et al. (2006a) compared boldness and shoaling tendency between wild $\left(\mathrm{F}_{2}\right)$ and laboratory zebrafish ( $\mathrm{AB}$ line). The $\mathrm{AB}$ fish showed reduced shoaling tendency and increased boldness compared to wild fish, presumably as a result of relaxed selection for anti-predator behaviours. Robison \& Rowland (2005) similarly compared the 
Nadia wild $\left(\mathrm{F}_{5}\right)$ strain with a transgenic line TMI, which contains a green fluorescent protein transgene, allowing them to be visually distinguished from other strains in a mixed aquarium. They found that Nadia were less surface orientated, were more likely to freeze on the bottom of the aquarium when presented with a novel object, and were less likely to inspect novel objects compared to TMI fish. Hybrids between the two strains showed intermediate responses and inter-strain differences were still apparent among strains reared in mixed tanks, suggesting that the behaviour was not learned.

It is also possible that the results of both these studies reflect pre-existing strain differences and are not related to domestication. A further study using Nadia, TMI and an additional domesticated strain (SH) revealed significant inter-strain differences across five behavioural measures, although the observed relationships within strains were relatively weak and occasionally inconsistent (Moretz, Martins \& Robison, 2006, 2007). These observations, together with the inter-population differences among wild fish identified by Wright et al. (2003) indicate the need for caution in interpreting behaviours as indicative of particular behavioural patterns such as 'domestication'.

\section{LEARNING AND RECEIVER BIAS}

Learning mediates many aspects of animal behaviour, including social interactions, foraging, navigation and predator avoidance. In zebrafish, the preference for associating with other fish is innate while the preference for particular colour patterns is based on learned behaviour. Individuals raised in isolation do not display colour pattern preferences whereas cross-reared individuals prefer to associate with the colour pattern with which they were raised (Engeszer et al., 2004; Spence \& Smith, 2007). Moreover, the preference effect of cross-rearing does not persist once fish are housed in groups of the same colour pattern, so the early learned preference can be modified by later experience (McCann \& Carlson, 1982). Learned preferences are mediated by olfactory as well as visual cues; zebrafish can differentiate between familiar and unfamiliar conspecifics on the basis of odour and thus appear capable of individual recognition (Gerlach \& Lysiak, 2006).

The response shown by zebrafish to alarm substance is also innate but appears to function as a means of learned predator recognition. Alarm substance can initiate a conditioned response to an innocuous odour, such as morpholine, when the two are presented simultaneously (Suboski et al., 1990). Hall \& Suboski (1995a) further elicited a learned response to a visual cue by pairing alarm substance with a red light as well as with morpholine. Thus, conditioning can operate across different sensory modalities. Hall \& Suboski (1995b) also demonstrated second order conditioning whereby fish conditioned with alarm substance to respond to either light or morpholine, then learned to react to the second neutral stimulus when presented in combination with the first conditioned stimulus in the absence of alarm substance. The mechanism for communicating learned predator recognition appears to be classical conditioning, pairing of an unconditioned stimulus (alarm substance) with a conditioned stimulus (light or morpholine) to produce a conditioned response (alarm reaction). Conditioned responses can develop after a single trial, and a response can be obtained even when there is a time delay of several minutes between presentation of the unconditioned and conditioned stimuli (Korpi \& Wisenden, 2001). Further, conditioned responses can be passed on to naïve fish, a process known as social

facilitation. Naïve fish exposed to morpholine when in the company of morpholine sensitized fish subsequently display an alarm reaction to morpholine. The naïve fish 
retain this learned response when solitary or in the company of a new group of naïve fish (Suboski et al., 1990).

An alternative approach to studying learning is to use an operant conditioning paradigm, whereby fish are trained to swim in a specific direction for a food reward paired with a visual cue. This approach has been used to study spatial memory, landmark use and orientation in other species (Braithwaite, 1998), and the few studies available indicate that zebrafish are potentially a useful model for research in this area. In a study to investigate spatial learning and memory, Williams, White \& Messer (2002) trained adult zebrafish to swim alternately to one or other side of a divided aquarium to receive a food reward. Once trained, the fish could remember the task after a 10-day period during which they were fed ad libitum in another aquarium. Zebrafish were also able to learn to swim into one of three compartments when the one containing the reward was cued by a white light (Bilotta et al., 2005). A threechoice design provides better evidence of learning than a two-choice design as the level of a chance response is reduced to a third. Williams et al. (2002) reported that fish learned the task in approximately 14 trials, although Bilotta et al. (2005) reported wide individual variability in speed of learning. When food rewards were withheld, the training effect was quickly lost (Williams et al., 2002; Colwill et al., 2005).

Little is known about the development of learning capacity. Williams et al. (2002) found that age affected acquisition of conditioned responses in zebrafish. Juveniles of 6-8 weeks learned the task as well or better than adults, whereas those of 3-4 weeks were not able to do so. It was not clear whether this was a result of limited cognitive capacity or because the task presented to fish was too physically demanding. A related question, which has not been investigated in zebrafish, is the extent to which habitat complexity during rearing influences cognitive development. Research with other fishes and comparisons among populations suggests that learning in fish may be related to the demands of their environment (Odling Smee \& Braithwaite, 2003).

The majority of studies of learning involve testing individual fish (Braithwaite 2005). However, in a shoaling species like zebrafish, fish may perform better in groups; the stress of being isolated may inhibit learning ability in isolated individuals. Moreover, fish are known to be able to learn by watching others (Brown \& Laland, 2003). However, Gleason, Weber \& Weber (1977) found that while zebrafish learned an avoidance response to an electric shock fastest in groups of five or more, single fish learned faster than pairs. Thus the relationship between learning and group size may not be straightforward. Steele, Scarfe \& Owens (1991) obtained similar results in exploratory feeding behaviour in response to alanine, a ubiquitous amino acid in the aquatic environment that functions as a chemical attractant and is the primary constituent of many prey odours. They found that the fastest response was elicited in groups of four fish, but single fish responded faster than groups of two, six or eight. Group size has not been studied in relation to spatial learning in zebrafish.

Miklósi \& Andrew (1999) used beads of different colours and patterns to study the effects of habituation to stimuli. Based on video footage of zebrafish biting responses they concluded that habituation is mediated by cerebral lateralisation of function; responses are controlled by different cerebral hemispheres under different circumstances. In trials, fish initially approached the bead with the right eye but in subsequent trials, once the object was familiar, used their left eye. Miklósi \& Andrew concluded that right hemisphere control (i.e. left eye) mediates escape/attack responses (automatic behaviour), whereas left hemisphere (right eye) control is used in assessing novel stimuli and involves the inhibition of Mauthner cell discharge. 
Many studies of learning are based on the use of neutral stimuli. However, in many species, innate receiver biases have evolved that cause them to respond more strongly to certain stimuli, and thus affect learning outcomes. Biases can exist at any level along the signal reception and processing continuum from stimulation of a primary sensory receptor to synthesis at higher levels of integration, including learning, memory and decision making (Basolo, 2000). Both learned preferences and innate receiver biases operate in the context of foraging. Spence \& Smith (in review) raised groups of fish on diets consisting solely of one colour: red, blue, green or white. When fish were subsequently tested for their colour preferences in a foraging context, each group responded most strongly to red, irrespective of the colour of food with which they had been conditioned. However, there was also a significant effect of conditioning. The observed sensory bias towards red may have evolved as a function of the nature of the transmission environment that zebrafish inhabit, in combination with an adaptive preference for carotenoid compounds in their diet (Spence \& Smith, in review).

Different tasks have been shown to elicit different preferences. Colwill et al. (2005) used a T-maze with different coloured arms (green versus purple or red versus blue) to assess visual discrimination learning in zebrafish. They found that while fish could be trained to swim down whichever coloured arm was associated with a food reward, they learned faster and retained the response longer when the colour associated with the reward was purple or blue than when it was green or red. Thus, not only were the stimuli not perceived as equal, but the colour preferences shown in this context differed from those in the foraging study by Spence \& Smith (in review). Similarly, two studies reached different conclusions about whether zebrafish prefer a dark or light environment. Serra, Medalha \& Mattioli (1999) found that zebrafish spent more time in a black chamber than a white one and concluded that they have an innate preference for dark environments. In contrast, Gerlai et al. (2000) concluded that zebrafish did not prefer a dark environment; fish initially avoided a dark chamber and on habituation spent equal amounts of time in illuminated and dark chambers. Clearly, the existence of innate preferences needs to be understood when designing behavioural protocols for learning studies in zebrafish.

\section{GENETIC BASIS OF BEHAVIOUR}

The relationship between genes and complex behaviours is not straightforward (Sokolowski, 2001). Behavioural syndromes comprise numerous individual components, involving multiple, interacting genes whose expression is influenced by the environment. The starting point in such research is to identify behavioural syndromes that can be quantified, with simple, reliable protocols that allow high throughput screening, either for mutagenesis or naturally occurring behavioural variation. Much of the pioneering behavioural genetics research has utilised Drosophila as a model; genes have been identified that control complex syndromes such as learning and memory, mating behaviour and circadian rhythms (Sokolowski, 2001; Anholt \& Mackay, 2004). The advent of functional genomics has enabled research to be extended to other species (Fitzpatrick et al., 2005; Vasemägi \& Primmer, 2005).

In comparison, there is a paucity of studies on complex behaviour in zebrafish, although it is recognised as having great potential as a model for understanding the genetic basis of human behavioural disorders (Patton \& Zon, 2001; Guo, 2004). One area of interest has been the effect of drugs of abuse on behaviour. Darland \& Dowling (2001) conducted a behavioural screen for cocaine addiction using the 
conditioned place preference paradigm (CPP), whereby the drug is paired with a neutral stimulus in one compartment of the aquarium and the amount of time the fish spends in each compartment is measured before and after administration of the drug. Three out of eighteen families of mutagenised fish showed abnormal responses in the CPP and were subjected to further behavioural screens, testing spatial cognition in a T-maze, swimming behaviour, and sensitivity to light. Each family had different behavioural profiles, which were shown to be heritable, each supposed as representing a different single gene mutation that affected addiction (Darland \& Dowling, 2001). Lau et al. (2005) used CPP to demonstrate a preference by wild-type zebrafish for both food and morphine as rewards. In contrast, the too few mutant, in which the basal forebrain DA and 5HT neurons are selectively reduced, lacked the morphine preference, while still displaying a preference for food. This result, whereby a single gene mutation can dissociate the preference for a natural reward and an addictive drug, indicates that the two preferences are controlled by different pathways.

Gerlai et al. (2000) designed a series of simple, easily quantifiable tests to examine the effects of alcohol administered at different concentrations on locomotion, aggression, shoaling tendency, alarm response, light/dark preference and pigmentation. These tests could be used to identify individuals with abnormal responses to alcohol. Dlugos \& Rabin (2003) compared the effects of acute and chronic alcohol administration on three zebrafish strains. The strains differed in startle response and shoal cohesion, suggesting that there is a genetic basis to both initial sensitivity and the development of tolerance to alcohol.

Zebrafish may also be a suitable model for studying the genetic basis of social behaviour. Larson et al. (2006) showed that there are clear differences between dominant and subordinate fish in the expression of arginine vasotocin, a neurohormone known to mediate social behaviour such as aggression, courtship and parental behaviour in vertebrates, although the system varies among taxa. Dominance relationships are not fixed and must, therefore, involve differential expression of different genetic pathways.

Tropepe \& Sive (2003) suggested that a forward genetics screening approach might be employed to model the behavioural deficits involved in autism using zebrafish. As deficits in social behaviour are strongly characteristic of autism, behaviours such as courtship and shoaling may represent a suitable paradigm for sociability. In mice, tests of exploratory behaviour have been used as a paradigm for anxiety and fear, exploratory behaviour tending to be negatively correlated with anxiety (Flint et al., 1995). Using a similar approach, Wright et al. (2006a) utilised the pronounced differences between wild and laboratory strains of zebrafish in willingness to approach an unfamiliar object (boldness) and attempted to identify quantitative trait loci associated with these.

Other complex behaviours that offer potential for genetic analysis are learning and memory. Protocols where fish are trained to swim in a particular direction for a food reward can be used to assess speed of learning and retention time between different strains of fish, fish reared under different conditions, or known behavioural mutants. These protocols have also been used to assess the effects of drugs of abuse on learning and memory (Swain, Sigstand \& Scalzo, 2004; Levin \& Chen, 2004). Genetic analysis of cerebral lateralisation of function may offer insights into the molecular basis of habituation. For instance, the mutant frequent situs inversus ( $f s i$ ), which shows reversal of asymmetry in many cerebral and visceral organs, showed reversal of behavioural asymmetry in some tests but not others, suggesting that at least two different mechanisms are involved in lateralisation of function (Barth et al., 2005). 
Studying the function of specific genes requires mutagenesis for gene knock-out or the application of gene silencing techniques such as morpholino injections or RNAi methodology. Techniques such as antisense, morpholino-modified oligonucleotides have been used successfully to silence targeted genes in zebrafish (Nasevicius \& Ekker, 2000). Morpholino oligos are short chains of morpholino subunits comprised of a nucleic acid base, a morpholine ring and a non-ionic phosphorodiamidate intersubunit linkage. Morpholinos act via a steric block mechanism (RNAse $\mathrm{H}$ independent) and, with their high mRNA binding affinity and exquisite specificity, they yield reliable and predictable results. They can either block the translation initiation complex (by targeting the 5' UTR through the first 25 bases of coding sequence) or they can block the nuclear splicing machinery (by targeting splice junctions in pre-mRNA). Microinjection of morpholino oligonucleotides into zebrafish embryos successfully and specifically shuts down the expression of targeted genes. However, due to the dilution effect of the morpholino oligonucleotide during cell proliferation, the gene silencing effect in developing zebrafish larvae only lasts for the first 3-4 days. Thus morpholinos cannot be applied to behavioural studies.

The discovery that double stranded RNA (dsRNA) can function to regulate gene expression has significant implications for the scientific research community from evolutionary biology to human therapeutics. This process is termed variously as RNA interference (RNAi), PTGS (post-transcriptional gene silencing) and quelling. The phenomenon was first described by researchers who achieved sequence specific gene silencing in Caenorhabditis elegans by injecting dsRNA that corresponded to the target sequence (Fire et al. 1998). In zebrafish, microinjection of long dsRNA has been used to silence genes with mixed results. In several instances non-specific effects and high mortality were observed (Oates, Bruce \& Ho, 2000; Zhao et al., 2001), probably due to the vertebrate specific immune response described above. However, in three studies, long dsRNA effectively silenced genes (Acosta et al., 2005; Li et al., 2000; Wargelius, Ellingsen \& Fjose, 1999).

Synthetically produced siRNA (21 nt), used for vertebrate cell line application, can down-regulate gene expression in zebrafish (Dodd, Chambers \& Love, 2004; Liu et al., 2005). Specificity of gene silencing using siRNA was shown in rainbow trout (Oncorhynchus mykiss) where a 4 base mismatch did not show any silencing effect while dsRNA could silence tryosinase A by $>80 \%$ (Boonanuntanasarn, Yoshizaki \& Takeuchi, 2003). While these studies clearly demonstrate the potential for RNAi technology as a tool in zebrafish research, they focus on genes expressed during very early development; none of the studies tested mRNA reduction later than $30 \mathrm{hpf}$. However, the phenotypic effects of myostatin silencing in zebrafish do suggest the possibility of prolonged effectiveness (into adulthood) (Acosta et al., 2005).

MicroRNAs (miRNAs), small single-stranded regulatory RNAs capable of interfering with intracellular messenger RNAs (mRNAs) with complete or partial complementarity, are useful for the design of new therapies against cancer polymorphisms and viral mutations. Lin, Miller \& Ying (2006) showed that intronderived miRNAs are able to induce RNA interference in zebrafish cells as well as those of humans and mice, demonstrating the evolutionary conservation of intronmediated gene silencing via functional miRNA in cell and in vivo. These findings suggest an intracellular miRNA-mediated gene regulatory system, fine-tuning the degradation of protein-coding messenger RNAs. Once established this may prove an invaluable technique in exploiting the potential of zebrafish as a model for studying complex behavioural patterns. 


\section{RESEARCH PRIORITIES}

\section{(1) Field-based studies}

While the three surveys reported here have provided basic information about zebrafish ecology (McClure et al., (2006); Spence et al., 2006a; Engeszer et al. 2007a), there is a need for more field based studies. The current distribution status of the zebrafish is unknown as recent studies have concentrated solely on the Ganges and Brahmaputra river systems. In addition, sampling from a wide range of populations would enable the cataloguing of natural variation in morphological, physiological and behavioural traits. This should include comparing the behaviour of zebrafish from a number of populations with different environmental parameters and predator regimes, as has been done with guppies (Magurran 2005). For instance, interpopulation differences in anti-predator behaviours (such as those identified by Wright et al., 2003) may relate to actual differences in natural predator regime.

Field observations of zebrafish behaviour would also prove invaluable and could supplement more detailed laboratory observations, providing definitive data on intraand inter-specific interactions. This objective requires the identification of field sites suitable in terms of accessibility and water clarity.

\section{(2) Behavioural studies}

The number of behavioural studies of zebrafish looks set to increase, and many researchers whose primary expertise is in genetics or developmental biology are utilising behavioural protocols, such as CPP as a paradigm for testing the reinforcing properties of drugs of abuse. One of the problems with designing and conducting behavioural experiments is demonstrating that the results are a valid measure of the behaviour under consideration. Thus there is a need for adequate controls, in order to ensure that the results are not due to unrelated artefacts (Nincovic \& Bally-Cuif, 2006); slight differences in experimental design and set-up can produce different results. For instance, preference tests need to take innate biases into account. Precision of measurement may also determine whether a preference is detected. Other sources of error include outside disturbance, either visual or auditory, and general handling of subjects, including acclimatisation. Behaviour may vary according to time of day at which observations are recorded, especially in relation to mating behaviour and feeding regime.

There is growing evidence for behavioural differences among zebrafish populations, even among domesticated strains. Loucks \& Carvan (2004) found strainand dose- dependent differences in sensitivity to developmental ethanol exposure between EK, AB TU strains. Moreover, each strain responded differently on different parameters, no single strain being most or least sensitive. Moretz et al. (2006, 2007) found differences among three strains, one wild-derived (Nadia) and two domesticated (TM1and SH) in shoaling, activity level, predator approaches, latency to feed after disturbance and biting at a mirror stimulus. Thus observed differences between wild and domesticated strains cannot all be ascribed to the effects of domestication.

In addition to the need for adequate controls, behavioural results are also dependent on a degree of experimenter interpretation, and this is perhaps the most difficult aspect to validate. Mating behaviour is the most straightforward to validate as observed behaviours can be correlated with egg production and parentage determined if necessary. Other behaviours are more difficult to validate. For instance, is biting at a mirror indicative of aggression (Gerlai et al. 2000) or purely an attempt to interact with a conspecific? (Moretz et al. 2006). 


\section{(3) Husbandry and welfare}

Given the paucity of data on the natural history of the zebrafish, it is not altogether surprising that husbandry protocols for this species are poorly developed; scientifically-based culturing strategies must be grounded in detailed knowledge of the ecology and behavior of the animal in question. Despite this, the zebrafish has become a pre-eminent research model, in large part because of its tolerance of a wide range of environmental conditions and the ease with which large numbers of eggs can be produced in the laboratory on a daily basis all year round. However, zebrafish are like any other cultured fish species in that there are a restricted set of parameters under which performance is optimised. All areas of zebrafish research would greatly benefit from improvements and standardization of husbandry practices (Lawrence 2007). In addition to achieving greater production and efficiency in research, the establishment of biologically justifiable practices for zebrafish culture would also address important concerns regarding zebrafish welfare that are currently sadly lacking.

There are numerous areas of zebrafish husbandry where information on their natural history and behavior may be applied to this end. The first of these concerns the physico-chemical requirements of zebrafish in research facilities. While the great majority of zebrafish facilities adhere to some derivation of water quality recommendations given by Westerfield (1995) and Matthews, Trevarrow \& Matthews (2002), these values are not based upon peer-reviewed data and, therefore, may not accurately reflect the requirements of the species. Information on the physical and chemical properties of natural habitats (McClure et al., 2006; Spence et al., 2006a) of zebrafish may be directly applied to the design of optimum water chemistry parameters for zebrafish in culture, as production in captivity may be highest when fish are kept in water quality regimes that most closely reflect that to which they are adapted in nature (Buttner, Soderbedrt \& Terlizzi, 1993).

Another important area of zebrafish husbandry is the induction of spawning in captivity. Despite their proclivity to reproduce under a wide range of conditions, zebrafish display complex breeding behavior (Darrow \& Harris, 2004), involving competition among both males and females (Spence \& Smith, 2005; Gerlach, 2006), as well as preference for mates (Pyron, 2003; Gerlach \& Lysiak, 2006; Spence \& Smith, 2006), spawning substrate (Spence et al., 2007b), and water depth (C. Lawrence \& A. Sessa, pers. obs.). Thus, egg production is negatively affected by density (Spence \& Smith, 2005; Gerlach, 2006), while egg production by pairs of fish may be dependent on individual compatibility (Spence \& Smith, 2006). Commonly utilized spawning methods and equipment (Mullins et al., 1994; Westerfield, 1995) may not take account of these factors, and thereby may result in reduced breeding efficiency, and/or the production of embryos of suboptimal or inconsistent quality. While it may not always be possible to incorporate behavioral and natural history data into breeding protocols (as, for instance, in the case of genetic studies which require sib mating), even simple efforts to replicate natural situations and facilitate behavioral preferences, for example by the addition of spawning substrate and plastic plants (Spence et al., 2007b) and the presentation of shallow areas in which to spawn (C. Lawrence \& A. Sessa, pers. obs.), may improve productivity.

With the exception of their requirement for poly-unsaturated fatty acids (Meinelt et al., 1999, 2000; Tocher et al., 2001) the nutritional demands of zebrafish are also unknown. Consequently zebrafish are often fed diets specifically formulated for other species (e.g. Matthews et al., 2002), which may place constraints on important aspects 
of their biology (Lovell, 1991). Gut content analysis of wild zebrafish indicates that they are omnivores, but feed primarily on insects and microcrustacea (McClure et al., 2006, Spence et al., 2007a). This finding provides some support for the practice of feeding zebrafish on Artemia nauplii (Carvalho, Araujo \& Santos, 2006), albeit these are species that zebrafish would not naturally encounter. Bloodworm is perhaps a more appropriate live food, as aquatic larval diptera are abundant items in the natural diet of zebrafish, although its size limits its use to adult fish. Gut content analysis also shows that in nature, while zebrafish feed primarily in the water column, they are also able to feed at the surface and on the substrate (McClure et al., 2006, Spence et al., 2007a). However, in the laboratory at least, zebrafish do not forage extensively on the substrate and overfeeding can result in a build-up of uneaten food on the aquarium floor and consequent reduction in water quality. These and further observations may aid in the formulation of artificial feeds most appropriate for zebrafish at different life stages, both in terms of nutritional profile and physical attributes (floating versus sinking, etc.) of food items.

Another important element of zebrafish husbandry is larval rearing. Current practices vary widely, but most generally involve presenting first-feeding larvae with a mixture of ciliates, rotifers, Artemia nauplii, and formulated microparticle diets, with progressive increases in percentages of the latter two as the animals undergo metamorphosis (Brown, 1997). Water quality during this period is of paramount importance, as the demand for the larvae to feed on a nearly constant basis must be balanced with the elimination of toxic waste products via water exchange and filtration. This problem is exacerbated by the fact that infusoria production requires water rich in organic material.

Although virtually nothing is known about the natural ecology of larval zebrafish, observations of wild zebrafish spawning along the margins of ponds (R. Spence \& C. Smith, pers. obs.) suggest that eggs may often be deposited in shallow, warm, waters rich with zooplankton and organic material. Further research in this area may assist in determining the most appropriate parameters for larviculture in terms of flow rates, organic loads, water chemistry, physical environment and dietary inputs. Information on larval behavior in laboratory conditions may also be useful for improving rearing protocols. For example, larval fish prefer the odours of kin to non-kin (Gerlach \& Lysiak, 2006), suggesting that fish initially reared with siblings or close relatives may perform better than those grown in mixed-kin groups.

The social environment of captive zebrafish is another parameter to be considered in relation to their husbandry and welfare. In the majority of zebrafish research facilities, little thought is given to the physical surroundings of the fish; tanks are typically bare, and densities are variable and are generally determined by growth rates (C. Lawrence, pers. obs.). As a shoaling species, it is generally presumed that zebrafish do better when kept in groups, although they do exhibit antagonistic behavior and form dominance hierarchies in laboratory conditions (Larsen et al., 2005, Gerlach, 2006). While aggression generally seems to be inversely correlated with density (Gillis \& Kramer, 1987; Chapman \& Kramer, 1995) zebrafish also show an elevation in circulating levels of the stress hormone cortisol when they are subjected to crowded conditions (Ramsay et al., 2006), suggesting that intermediate densities may be the most favourable. The provision of refugia, such as artificial plants, in holding tanks may further offset the potentially negative effects of aggression. In nature, zebrafish are often associated with aquatic vegetation (Spence et al., 2006a), a preference that is also seen in laboratory populations (Delaney et al., 2002). These observations, along with experimental evidence demonstrating that 
aggression and monopolization of food resources by dominant individuals is decreased in structurally complex environments (Basquill \& Grant, 1998), further strengthens the argument that the practice of adding complexity to aquaria may improve the long-term well-being of laboratory zebrafish, though this has yet to be demonstrated experimentally.

\section{CONCLUSIONS}

(1) Zebrafish appear to be primarily a floodplain species, inhabiting shallow ponds and ditches or the slower reaches of streams. They are an abundant species and are among the smallest fish species in the assemblages in which they occur. Their diet, based on gut content analysis, consists primarily of insects (of both terrestrial and aquatic origin) and zooplankton, as well as inorganic material. These results indicate that they feed throughout the water column, consistent with observations of their vertical distribution, and the finding that they tend to be confined to the shallow margins of waterbodies.

(2) The zebrafish is known for its rapid development in the laboratory. Lengthfrequency analysis indicates that under natural conditions the zebrafish is an annual species and recruitment is linked to the monsoon, which is also the period of the year with the highest temperatures. The most rapid growth takes place in the first three months, and slows thereafter, virtually ceasing by about 18 months. Breeding may be dependent on food availability rather than season, as gravid females have been found in Bangladesh in winter and wild-caught zebrafish breed all year round in the laboratory.

(3) Zebrafish reproductive behaviour has been studied almost exclusively in the laboratory on domesticated strains, although an experiment conducted with wildcaught fish under semi-natural conditions confirms that the mating behaviours described are broadly applicable in nature. Zebrafish have previously been characterised as group spawners and egg scatterers, although there is evidence that the mating system is influenced by both intra-sexual competition and female mate preferences. Further, competition for high quality sites for oviposition may be a key feature of mating behaviour in nature. Given the role of pheromones in zebrafish reproduction and evidence from other published behavioural studies (Gerlach 2006; Gerlach \& Lysiak 2006), these may play a role in mate choice; in particular, the zebrafish may be a suitable model for studying the role of MHC in mate choice. However, the zebrafish has little to offer as a model for sexual selection compared to other fish behavioural models such as guppies, sticklebacks or bitterling. The opportunity for sexual selection appears to be weak in zebrafish, as might be predicted from their lack of marked sexual dimorphism.

(4) The greatest advantage of the zebrafish as a model system comes from its well-characterised genetics, genetic and developmental techniques and tools, and the availability of well-characterised mutants. Zebrafish are also a tractable species for behavioural experiments, readily acclimatising to new environments, being constantly active and little disturbed by the presence of observers. In order for the zebrafish to be more widely adopted as a model by the behavioural ecology community there is a need for more behavioural and field-based studies in order to catalogue natural variation in morphological, physiological and behavioural traits. The zebrafish appears ideally suited to studies of social and cognitive behaviour, and it is surprising that it has been so little utilised for this purpose. There is increasing interest in employing social and cognitive tests with zebrafish to study the genetic basis of 
behaviour and there is a need for more comprehensive and better controlled studies in this area.

\section{ACKNOWLEDGEMENTS}

The authors are grateful to Dave Parichy for his valuable comments on the manuscript.

\section{REFERENCES}

ACOSTA, J., CARPIO, Y., BORROTO, I., GONZALEZ, O. \& ESTRADA, M. P. (2005). Myostatin gene silenced by RNAi show a zebrafish giant phenotype. Journal of Biotechnology 119, 324-331 .

Amsterdam, A. \& HopKIns, N. (2006). Mutagenesis strategies in zebrafish for identifying genes involved in development and disease. Trends in Genetics 22, 473-478.

Amsterdam, A., Burgess, S., Golling, G., Chen, W., Sun, Z., Townsend, K., FARRINGTON, S., HALDI, M., AND HopKINS, N. (1999) A large scale insertional mutagenesis screen in zebrafish. Genes and Development 13, 2413-2724.

ANHOLT, R. R. H. \& MACKAY, T. F. C. (2004). Quantitative genetic analysis of complex behaviours in Drosophila. Nature Reviews Genetics 5, 838-849.

Baganz, D., Siegmund, R., StaAks, G., Pflugmacher, S. \& Steinberg, C. E. W. (2005). Temporal pattern in swimming activity of two fish species (Danio rerio and Leucaspius delineatus) under chemical stress conditions. Biological Rhythm Research 36, $263-276$

BarbazuK, W. B., Korf, I., Kadavi, C., Heyen, J., Tate, S., Wun, E., Bedell, J. A., McPherson, J. A. \& Johnson, S. L. (2000). The syntenic relationship of the zebrafish and human genomes. Genome Research 10, 1351-1358.

BARINAGA, M. (1990). Zebrafish: swimming into the developmental mainstream. Science 250, 34-35.

BARINAGA, M. (1994). Looking into development's future. Science 266, 561-564.

BARMAN, R. P. (1991). A taxonomic revision of the Indo-Burmese species of Danio rerio. Record of the Zoological Survey of India Occasional Papers 137, 1-91.

BARTH, K. A., MikLÓsi, A., WATKins, J., BiAnCO, I. H., Wilson, S. W. \& ANDREW, R. J. (2005). fsi zebrafish show concordant reversal of laterality of viscera, neuroanatomy, and a subset of behavioral responses. Current Biology 15, 844850.

BAsolo, A. L. (2000). Problems in studying receiver biases and their effects on signal evolution. In Animal signals: signalling and signal design in animal communication. (eds. Y. Epsmark, T. Amundsen and G. Rosenqvist.), pp. 177193. Trondheim, Tapir Academic Press.

BASQUILL, S. P. \& GRANT, J. W. A. (1998). An increase in habitat complexity reduces aggression and monopolization of food by zebra fish (Danio rerio). Canadian Journal of Zoology 76, 770-772.

Berghmans, S., JetTe, C., Langenau, D., Hsu, K., Stewart, R., LoOK, T. \& Kanki, J.P. (2005). Making waves in cancer research: new models in the zebrafish. Biotechniques 39, 227-237.

Bilotta, J., Risner, M. L., Davis, E. C. \& Haggbloom, S. J. (2005). Assessing appetitive choice discrimination learning in zebrafish. Zebrafish 2, 251-268. 
Bloom, H. D. \& Perlmutter, A. (1977). A sexual aggregating pheromone system in the zebrafish, Brachydanio rerio (Hamilton-Buchanan). Journal of Experimental Biology 199, 215-226.

Boonanuntanasarn, S., Yoshizaki, G., \& TAKeuchi, T. (2003). Specific gene silencing using small interfering RNAs in fish embryos. Biochemical and Biophysical Research Communications 310, 1089-1095.

BraithWAite, V. A. (1998). Spatial memory, landmark use and orientation in fish. In Spatial representation in animals. (ed. S. Healy), pp 86-102. Oxford University Press, Oxford.

Braithwaite, V.A. (2005) Cognitive ability in fish. Fish Physiology 24, 1-37.

BREDER, C. M. \& Rosen, D. E. (1966). Modes of reproduction in fishes. New York, Natural History Press.

BRown, D.D. (1997). The role of thyroid hormone in zebrafish and axolotl development. Proceedings of the National Academy of Sciences of the USA 94, 13011-13016.

Brown, C. \& LALAND, K. (2003). Social learning in fishes: a review. Fish and Fisheries 4, 280-288.

ButTNER, J.K., SODERBERG, R.W., \& TerLIZZI, D. E. (1993). An introduction to water chemistry in freshwater aquaculture. Northeastern Regional Aquaculture Center, Fact Sheet No. 70.

Carvalho A. P., Araujo, L., \& Santos, M. M. (2006). Rearing zebrafish (Danio rerio) larvae without live food: evaluation of a commercial, a practical, and a purified starter diet on larval performance. Aquaculture Research 37, 1107-1111.

ChAPMAN, M. R., \& KRAMER, D. L. (1996). Guarded resources: the effect of intruder number on the tactics and success of defenders and intruders. Animal Behaviour 52 83-94.

Chen, E. \& Ekker, S. C. (2004). Zebrafish as a Genomics Research Model. Current Pharmaceutical Biotechnology 5, 409-413.

Colwill, R. M., RAYmond, M. P., Ferreira, L. \& Escudero, H. (2005). Visual discrimination learning in zebrafish (Danio rerio). Behavioural Processes 70, 1931.

CREASER, C. W. (1934). The technique of handling the zebrafish (Brachydanio rerio) for the production of eggs which are favourable for embryological research and are available at any specified time throughout the year. Copeia 1934, 159-161.

Daniels, R. J. R. (2002). Freshwater fishes of peninsula India. Universities Press, Hyderabad.

DARLAND, T. \& DOWLING, J. E. (2001). Behavioral screening for cocaine sensitivity in mutagenized zebrafish. Proceedings of the National Academy of Sciences of the USA 98, 11691-11696.

DARROW, K. O. \& HARRIS, W. A. (2004). Characterisation and development of courtship in zebrafish, Danio rerio. Zebrafish 1, 40-45.

Delaney, M., Follet, C., RyAn, N., HANNEY, N., LUSK-YABliCK, J., AND GERLACH, G. (2002). Social interaction and distribution of female zebrafish (Danio rerio) in a large aquarium. Biological Bulletin 203, 240-241.

Detrich, H.W. III, WeSTERFIELD, M., AND ZON, L.I. (1999) The zebrafish: biology. Academic Press, San Diego.

DeVlin, R. H. \& Nagahama, Y. (2002). Sex determination and sex differentiation in fish: an overview of genetic, physiological, and environmental influences. Aquaculture 208, 191-364. 
DiLL, L. M. (1974a). The escape response of the zebra danio (Brachydanio rerio) I. The stimulus for escape. Animal Behaviour 22, 711-722.

DiLL, L. M. (1974b). The escape response of the zebra danio (Brachydanio rerio) II. The effect of experience. Animal Behaviour 22, 723-730.

Dlugos, C. A. \& RABIN, R. A. (2003). Ethanol effects on three strains of zebrafish: model system for genetic investigations. Pharmacology, Biochemistry and Behavior 74, 471-480.

DodD, A., Chambers, S. P. \& Love, D. R. (2004). Short interfering RNA-mediated gene targeting in the zebrafish. FEBS Letters 561, 89-93.

DoOley, K. \& Zon, L. I. (2000). Zebrafish: a model system for the study of human disease. Current Opinion in Genetics and Development 10, 252-256.

Driever, W., Solnica-Krezel, L., Schier, A. F., Neuhauss, S. C. F., Malicki, J., Stemple, D. L., Stainier, D. Y. R., ZWARTKRUis, F., AbDelilah, S., RANGini, Z., BELAK, J. \& BoGGS, C. (1996). A genetic screen for mutations affecting embryogenesis in zebrafish. Development 123, 37-46.

DutTA, S. P. S. (1993). Food and feeding habits of Danio rerio (Ham. Buch.) inhabiting Gadigarh stream, Jammu. Journal of Freshwater Biology 5, 165-168.

EATON, R. C. \& FARLEY, R. D. (1974b). Spawning cycle and egg production of zebrafish, Brachydanio rerio, in the laboratory. Copeia 1974, 195-204.

EATON, R. C. \& FARLEY, R. D. (1974a). Growth and reduction of depensation of the zebrafish Brachydanio rerio, reared in the laboratory. Copeia 1974, 204-209.

EgGeRT, U.S., AND Mitchison, T.J. (2006) Small molecule screening by imaging. Current Opinion in Chemical Biology 10, 232-237

Engeszer, R. E., Alberici da BARBiAno, L., Ryan, M. J. \& PARICHY, D. M. (2007b). Timing and plasticity of shoaling behaviour in the zebrafish, Danio rerio. Animal Behaviour (in press).

Engeszer, R. E., PAtTerson, L. B., RAO, A. A. \& PARichy, D. M. (2007a) Zebrafish in the wild: a review of natural history and new notes from the field. Zebrafish 4, 21-40.

ENGESZER, R. E., RYAN, M. J. \& PARICHY, D. M. (2004). Learned social preference in zebrafish. Current Biology 14, 881-884.

FANG, F. (1998). Danio kyathit, a new species of cyprinid fish from Myitkyina, northern Myanmar. Ichthyological Exploration of Freshwaters 8, 273-280.

FANG, F. (2001). Phylogeny and species diversity of the South and Southeast Asian cyprinid genus Danio Hamilton (Teleostei, Cyprinidae). PhD Thesis, Stockholm University, Stockholm, Sweden.

FANG, F. (2003). Phylogenetic analysis of the Asian cyprinid genus Danio (Teleostei, Cyprinidae). Copeia 4, 714-728.

FitzPatrick, M. J., Ben-Shahar, Y., Smid, H. M., Vet, L. E. M., Robinson, G. E. \& SoKolowsKi, M. B. (2000). Candidate genes for behavioural ecology. Trends in Ecology and Evolution. 20, 96-104.

Flint, J., Corley, J. C., DeFries, J. C., Fulker, D. W., Gray, J. A., Miller, S., \& Collins, A. C. (1995). A simple genetic basis for a complex psychological trait in laboratory mice. Science 269, 1432-1435.

FRETWELL, S. D. \& LUCAS, H. L. (1970). On territorial behaviour and other factors influencing habitat distribution in birds. I Theoretical development. Acta Biotheoretica 19, 16-36.

Gerhard, G. S., Kauffman, E. J., Wang, X., Stewart, R., Moore, J. L., Kasales, C. J., Demidenko, E. \& Cheng, K. C. (2002). Life spans and senescent phenotypes of zebrafish (Danio rerio). Experimental Gerontology 37, 1055-1068. 
Gerlach G.\& LysiaK, N. (2006). Kin recognition and inbreeding avoidance in zebrafish, Danio rerio, is based on phenotype matching. Animal Behaviour 71, 1371-1377.

Gerlach, G. (2006). Pheromonal regulation of reproductive success in female zebrafish: female suppression and male enhancement. Animal Behaviour 72, 1119-1124.

GERLAI, R. (2003). Zebrafish: An uncharted behavior genetic model. Behavior Genetics 33, 461-468.

Gerlai, R., Lahav, M., Guo, S. \& Rosenthal, A. (2000). Drinks like a fish: zebrafish (Danio rerio) as a behavior genetic model to study alcohol effects. Pharmacology, Biochemistry and Behavior 67, 773-782.

GILliS, D. M. \& KRAMER, D. L. (1987). Ideal interference distributions: population density and patch use by zebrafish. Animal Behaviour 35, 1875-1882.

Gleason, P. E., Weber, P. G. \& WeBer, S. P. (1977). Effect of group size on avoidance learning in zebrafish, Brachydanio rerio, (Pisces: Cyprinidae). Animal Learning and Behavior 5, 213-216.

Golling, G., Amsterdam, A., Sun, Z., Antonelli, M., Maldonado, E., Chen, W., Burgess, S., Haldi, M., Artzt, K., Farrington, S., Lin, S., Nissen, R. AND HOPKINS, N. (2002). Insertional mutagenesis in zebrafish rapidly identifies genes essential for early vertebrate development. Nature Genetics 31, 135-140.

GolubEV, A. V. (1984). Role of chemical stimul in group and spawning behavior of zebrafish, Brachidanio rerio. Voprosy Ikhtiologii. 6, 1020-1027.

GOOLISH, E. M. \& OKUTAKE, K. (1999). Lack of gas bladder inflation by the larvae of zebrafish in the absence of an air-water interface. Journal of Fish Biology 55, 1054-1063.

Granato, M. \& Nusslein-Volmard, C. (1996). Fishing for genes controlling development. Current Opinion in Genetics and Development 6, 461-8.

GrANT, J. W. A. \& KRAMER, D. L. (1992). Temporal clumping of food arrival reduces its monopolization and defense by zebrafish, Brachydanio rerio. Animal Behaviour 44, 101-110.

GRUNWALD, D. J. \& EISEN, J. S. (2002). Headwaters of the zebrafish - emergence of a new model vertebrate. Nature Reviews Genetics 3, 717-724.

GuO, S. (2004). Linking genes to brain, behavior and neurological diseases: what can we learn from zebrafish? Genes, Brain and Behavior 3, 63-74.

Guyon, J.R., Steffen, L.S., Howell, M.H., Pusack, T.J., Lawrence, C., And KunKEL, L.M. (2006) Modeling human muscle disease in zebrafish. Biochimica et biophysica acta 1772, 205-215.

Haffter, P., Granato, M., Brand, M., Mullins, M. C., Hammerschmidt, M., Kane, D. A., Odenthal, J., Van Eeden, F. J. M., Jiang, Y. J., Heisenberg, C. P., Kelsh, R. N., Furutani-Seiki, M., Vogelsang, E., Beuchle, D., Schach, U., FABIAN, C. \& NÜSSLEIN-VOLHARD, C. (1996a). The identification of genes with unique and essential function in the development of the zebrafish, Danio rerio. Development 123, 1-36.

Haffter, P., Odenthal, J., Mullins, M. C., Lin, S., Farrell, M. J., Vogelsang, E., HaAs, F., Brand, M., van Eeden, F. J. M., Furutani-Seiki, M., Granato, M., Hammerschmidt, M., Heisenberg, C. P., Jiang, Y. J., Kane, D. A., Kelsh, R. N., Hopkins, N. \& NÜSslein-Volhard, C. (1996b). Mutations affecting pigmentation and shape of the adult zebrafish. Development Genes and Evolution 206, 260-276. 
HALL, D. \& SubOSKI, M. D. (1995a). Visual and olfactory stimuli in learned release of alarm reactions by zebra danio fish (Brachydanio rerio). Neurobiology, Learning and Memory 63, 229-40.

Hall, D. \& SubOSKI, M. D. (1995b). Sensory preconditioning and second order conditioning of alarm reactions in zebra danio fish. Journal of Comparative Psychology 109, 76-84.

Hamilton, I. M. \& DilL, L. M. (2002). Monopolization of food by zebrafish (Danio rerio) increases in risky habitats. Canadian Journal of Zoology 80, 2164-2169.

HisAOKA, K. K. \& FirLiT, C. F. (1962). Ovarian cycle and egg production in the zebrafish, Brachydanio rerio (Hamilton-Buchanan). Copeia 1962 788-792.

HoweS, G. J. (1991). Systematics and biogeography: an overview In Cyprinid fishes systematics, biology and exploitation. (eds. I. J. Winfield and J. S. Nelson), pp. 133. Chapman and Hall, London.

JAYARAM, K. C. (1999). The freshwater fishes of the Indian region. Narendra Publishing House, Delhi.

Kawakami, K., Amsterdam, A., Nobuyoshi, S., Becker, T., Mugg, J., Shima, A., \& Hopkins, N. (2000). Proviral insertions in the zebrafish hagoromogene, encoding an F-box/WD40-repeat protein, cause stripe pattern anomalies. Current Biology 10, 463-466.

Kelsh RN, Brand M, Jiang YJ, Heisenberg CP, Lin S, Haffter P, Odenthal J, Mullins MC, VAN EEDEN FJM, Furutani-SEIKI M, GRANATO M, Hammerschmidt M, Kane DA, Warga RM, Beuchle D, Vogelsang L, NuSSLEIN-VOLHARD C. (1996). Zebrafish pigmentation mutations and the processes of neural crest development. Development 123, 369-389.

Kent, M. L., Bishop-Stewart, J. K., Matthews, J. L. \& Spitzbergen, J. M. (2002). Pseudocapillaria tomentosa, a nematode pathogen and associated neoplasms of zebrafish (Danio rerio) kept in research colonies. Comparative Medicine. 52, 354358.

KERR, J. P. (1963). Grouping behaviour of the zebrafish as influenced by social isolation. American Zoologist 2, 532-533.

KiMMEL, C. B. (1989) Genetics and early development of zebrafish. Trends in Genetics 5, 283-288.

Kimmel, C. B., Ballard, W. W., Kimmel, S. R., Ullmann, B \& Schilling, T. F. (1995). Stages of embryonic development of the zebrafish. Developmental Dynamics 203, 253-310.

Kimmel, C. B., WARGA, R. M. \& SChILling, T. F. (1990).Origin and organization of the zebrafish fate map. Development 108, 581-594.

KimmeL, C.B. (1993) Patterning the brain of the zebrafish embryo. Annual Review of Neuroscience 16, 707-732.

Kishi S, Uchiyama J, Baughman A. M., Goto, T., Lin, M.C. \& Tsai, S.B. (2003) The zebrafish as a vertebrate model of functional aging and very gradual senescence. Experimental Gerontology, 38, 777-786.

Kitevski, B. \& Pyron, M. (2003). Female zebrafish (Danio rerio) do not prefer mutant longfin males. Journal of Freshwater Ecology 18, 501-502.

KoRPI, N. L. \& WiSENDEN, B. D. (2001). Learned recognition of novel predator odour by zebra danios, Danio rerio, following time-shifted presentation of alarm cue and predator odour. Environmental Biology of Fishes 61, 205-211.

Krause, J., HaRtManN, N. \& PRitChaRd, V. L. (1999). The influence of nutritional state on shoal choice in zebrafish, Danio rerio. Animal Behaviour 57, 771-775. 
LAALE, H. W. (1977). The biology and use of zebrafish, Brachydanio rerio in fisheries research. A literature review. Journal of Fish Biology 10, 121-173.

Lamason, R.L., Mohideen, M.A., Mest, J.R., Wong, A.C., Norton, H.L., Aros, M.C., Jurynec, M.J., MAO, X., Humphreville, V.R., Humbert, J.E., Sinha, S., Moore, J.L., Jagadeeswaran, P., ZhaO, W., Ning, G., MaKalowsKa, I., McKeigue, P.M., O'dOnnell, D., Kittles, R., Parra, E.J., Mangini, N.J., Grunwald, D.J., Shriver, M.D., CANFIEld, V.A., \& ChenG, K.C. (2005) SLC24A5, a putative cation exchanger, affects pigmentation in zebrafish and humans. Science 310, 1782-1786.

Larson, E. T., O’Malley, D. M. \& Melloni JR, R. H. (2006). Aggression and vasotocin are associated with dominant-subordinate relationships in zebrafish. Behavioural Brain Research 167, 94-102.

Lau, B., Bretaud, S., Huang, Y., Lin, E. \& Guo, S. (2006) Dissociation of food and opiate preference by a genetic mutation in zebrafish. Genes, Brain and Behaviour 5, 497-505.

LAWRENCE, C. (2007) The husbandry of zebrafish (Danio rerio): a review. Aquaculture 269, 1-20.

Lawrence, C., Ebersole, J. P. \& Kesseli, R. V. (2007) Rapid growth and outcrossing promote female development in zebrafish (Danio rerio). Environmental Biology of Fishes DOI: 10.1007/s10641-007-9195-8.

LeE, K. W., WebB, S. E. \& Miller, A. L. 1999. A wave of free cytosolic calcium traverses zebrafish eggs on activation. Developmental Biology 214, 168-180.

Levin, E. D. \& Chen, E. (2004). Nicotinic involvement in memory function in zebrafish. Neurotoxicology and Teratology 26, 731-735.

Li, Y. X., FARrell, M. J., LiU, R. P., Mohanty, N. \& Kirby, M. L. (2000). Doublestranded RNA injection produces null phenotypes in zebrafish. Developmental Biology 217, 394-405.

LIN, S. L., MiLleR, J. D. \& YING, S. Y. (2006). IntronicMicroRNA (miRNA). Journal of Biomedicine and Biotechnology 2006, Article ID 26818, 13 pages.

Lister, J. A., Robertson, C. P., Lepage, T., Johnson, S. L. \& RAible, D. W. (1999). nacre encodes a zebrafish microphthalmia-related protein that regulates neural crest-derived pigment cell fate. Development 126, 3757-3767.

LiU, W. Y., WANG, Y., Sun, Y. H., WANG, Y., WANG, Y. P., Chen, S. P. \& ZhU, Z. Y. (2005). Efficient RNA interference in zebrafish embryos using siRNA synthesized with SP6 RNA polymerase. Development Growth \& Differentiation 47, 323-331.

LOUCKS, E. \& CARVAN, M. J. (2004). Strain-dependent effects of developmental ethanol exposure in zebrafish. Neurotoxicology and Teratology 26, 745-755.

Lovell, R. T. (1991) Nutrition of aquaculture species. Journal of Animal Science 69, 4193-4200.

MAack, G. \& Segner, H. (2003). Morphological development of the gonads in zebrafish. Journal of Fish Biology 62, 895-906.

MagurRAn, A. E. (2005). Evolutionary ecology: the Trinidadian guppy. Oxford Series in Ecology \& Evolution. Oxford University Press, Oxford.

Marks, C. West, T. N. Bagatto, B. \& Moore, F. B. G. (2005). Developmental environment alters conditional aggression in zebrafish. Copeia 2005, 901-908.

Matthews, M., Trevarrow, B., \& Matthews, J. (2002) A virtual tour of the guide for zebrafish users. Lab Animal 31, 34-40.

MCCANN, L. I. \& CARLSON, C. C. (1982). Effect of cross-rearing on species identification in zebra fish and pearl danios. Developmental Psychobiology 15, 7174. 
MCCANn, L. I. \& MatTHEWS, J. J. (1974). The effects of lifelong isolation on species identification in zebra fish (Brachydanio rerio). Developmental Psychobiology 7, 159-163.

MCCLURE, M. 1999. Development and evolution of melanophore patterns in fishes of the genus Danio (Teleostei: Cyprinidae). Journal of Morphology 241, 83-105.

McClure, M. M., McIntyre, P. B. \& McCune, A. R. (2006). Notes on the natural diet and habitat of eight danionin fishes, including the zebrafish, Danio rerio. Journal of Fish Biology 69, 553-570.

Meinelt, T., Schultz C., Worth M., Kurzinger, H., \& Steinberg, C. (2000). Correlation of diets high in n6-polyunsaturated fatty acids with high growth rate in zebrafish (Danio rerio). Comparative Medicine 50, 43-45.

Meinelt, T., Schultz C., Worth M., Kurzinger, H., \& Steinberg, C. (1999). Dietary fatty acid composition influences the fertilization rate of zebrafish (Danio rerio Hamilton-Buchanon). Journal of Applied Ichthyology. 15,19-23.

Meinken, H. (1963). Brachydanio frankei spec. nov., der Leopard danio. Aquarium und Terrararien 10, 39-43.

Meyer, A., Biermann, C. H. \& Orti, G. (1993). The phylogenetic position of the zebrafish (Danio rerio), a model system in developmental biology: an invitation to the comparative method. Proceedings of the Royal Society of London, Series B 252, 231-236.

Meyer, A., Ritchie, A. P. \& Witte, K-E. (1995). Predicting developmental processes from evolutionary patterns: a molecular phylogeny of the zebrafish (Danio rerio) and its relatives. Philosophical Transactions of the Royal Society of London, Series B 349, 103-111.

MiKLÓsi A. \& ANDREW, R. J. (2006). The zebrafish as a model for behavioural studies. Zebrafish 3, 227-234.

MikLÓSI, A. \& ANDREW, R. J. (1999). Right eye use associated with decision to bite in zebrafish. Behavioural Brain Research 105, 199-205.

Moretz, J. A., Martins, E. P. \& RoBison, B. (2006). The effects of early and adult social environment on zebrafish (Danio rerio) behavior. Environmental Biology of Fishes DOI: 10.1007/s10641-006-9122-4.

Moretz, J. A., Martins, E. P. \& Robison, B. (2007). Behavioral syndromes and the evolution of correlated behaviour in zebrafish. Behavioral Ecology 18, 556-562.

Mullins, M.C., Hammerschmidt, M., HaffTer, P., AND NÜSSlein-VolHard, C. (1994). Large-scale mutagenesis in the zebrafish: in search of genes controlling development in a vertebrate. Current Biology 4, 189-202.

NASEVICIUS, A., EKKER, S. C. (2000). Effective targeted gene "knockdown" in zebrafish. Nature Genetics 26, 216-220.

NeLson, J. S. (1994). Fishes of the world. $3^{\text {rd }}$ edn. Wiley, New York.

NinKOVIC, J. \& BALLY-CUIF, L. (2006) The zebrafish as a model system for assessing the reinforcing properties of drugs of abuse. Methods 39, 262-274.

NÜSSlein-Volhard, C. \& DAHM, R. (2002). Zebrafish. Oxford University Press, Oxford.

OAtes, A. C., Bruce, A. E. E. \& Ho, R. K. (2000). Too much interference: Injection of double-stranded RNA has nonspecific effects in the zebrafish embryo. Developmental Biology 224, 20-28.

Odling-Smee, L. \& Braithwaite, V. A. (2003). The role of learning in fish orientation. Fish and Fisheries 4, 234-246.

PARICHY, D.M. (2006a). Evolution of danio pigment pattern development. Heredity 97, 200-210. 
PARICHY, D. M. (2006b). Homology and the evolution of novelty during Danio adult pigment pattern development. Journal of Experimental Zoology 306B, 1-13.

PARICHY, D. M. \& Johnson, S. L. (2000). Zebrafish hybrids suggest genetic mechanisms for pigment pattern diversification in Danio. Development, Genes and Evolution 211, 319-328.

PAtTON, E. E. \& ZoN, L. I. (2001). The art and design of genetic screens: Zebrafish. Nature Reviews Genetics 2, 956-966.

Petrovicky, I. (1966). Hybridization between Brachydanio rerio (HamiltonBuchanan) and Brachydanio frankei (Meinken). Ichthyologica 37, 53-62.

Pfeiffer, W. (1974) Pheromones in fish and amphibia. In: Pheromones (ed. M.C. Birch), pp. 269-296, North Holland Publishing Company, Amsterdam.

Pitcher, T. J., \& PARRISH, J. K. (1993). Functions of shoaling behaviour in teleosts. In: Behaviour of teleost fishes. (ed. T.J. Pitcher), pp. 363-439. Chapman and Hall, London.

PlaUT, I. (2000). Effects of fin size on swimming performance, swimming behaviour and routine activity of zebrafish Danio rerio. Journal of Experimental Biology 203, 813-820.

Postlethwait, J. H., Yan, Y-L., Gates, M. A., Horne, S. Amores, A. Brownlie, A. Donovan, A., Egan, E. S., Force, A., Gong, Z., Goute, C., Fritz, A., Kelsh, R., Knapik, E., Liao, E., PaW, B., Ransom, D., Singer, A., Thomson, M., AbduljabBar, T. S., Yelick, P., Beier, D., Joly, J. -S., LARHAmmar, D., Rosa, F., Westerfield, M., Zon, L. I., Johnson, S. L. \& TAlBot, W. S. (1998). Vertebrate genome evolution and the zebrafish gene map. Nature Genetics 18, 345-349.

PostlethWAit, J.H. \& TAlBOT, W.S. (1997). Zebrafish genomics: from mutants to genes. Trends in Genetics 13, 183-90.

PRITChARD, V. L. (2001). Behaviour and morphology of the zebrafish, Danio rerio. PhD thesis, University of Leeds.

Pritchard, V. L., LAWrenCE, J., Butlin, R. K. \& Krause, J. (2001). Shoal choice in zebrafish, Danio rerio: the influence of shoal size and activity. Animal Behaviour 62, 1085-1088.

Pyron, M. (2003). Female preferences and male-male interactions in zebrafish (Danio rerio). Canadian Journal of Zoology 81, 122-125.

Quigley, I. K. \& PARIChy, D. M. (2002). Pigment pattern formation in zebrafish: A model for developmental genetics and the evolution of form. Microscopy Research and Technique 58, 442-455.

RAmsay J. M., Feist, G. W, VARGA, Z. M., WESTERFIELD. M., KENT, M.L. \& SCHRECK, C. B. (2006) Whole-body cortisol is an indicator of crowding stress in adult zebrafish, Danio rerio Aquaculture 258, 565-574.

REHNBERG, B. G. AND R. J. F. SMITH (1988). The influence of alarm substance and shoal size on the behaviour of zebra danios, Brachydanio rerio (Cyprinidae). Journal of Fish Biology 33, 155-163.

Rhul, N. \& McRobert, S. P. (2005). The effect of sex and shoal size on shoaling behaviour in Danio rerio. Journal of Fish Biology 67, 1318-1326.

RoBison, B. D. \& Rowland, W. (2005). A potential model system for studying the genetics of domestication: behavioral variation among wild and domesticated strains of zebra danio (Danio rerio). Canadian Journal of Fisheries and Aquatic Sciences 62, 2046-2054.

Rosenthal, G. G. \& Ryan, M. J. (2005). Assortative preferences for stripes in danios. Animal Behaviour 70, 1063-1066. 
Rubinstein, A.L. (2003). Zebrafish: from disease modelling to drug discovery. Current Opinion in Drug Discovery Development 6, 218-223.

Rubinstein, A.L. (2006). Zebrafish assays for drug toxicity screening. Expert Opinion on Drug Metabolism \& Toxicology, 2, 231-240.

SANGER, T. J. \& MCCune, A. R. (2002). Comparative osteology of the Danio (Cyprinidae : Ostariophysi) axial skeleton with comments on Danio relationships based on molecules and morphology. Zoological Journal of the Linnean Society 135, 529-546.

SCHILLING, T. (2002). The morphology of larval and adult zebrafish. In: Zebrafish. (eds. C. Nüsslein-Volhard, \& R. Dahm) pp. 59-94. Oxford University Press, Oxford.

Serra, E. L., Medalha, C. C. \& Mattioli, R. (1999). Natural preference of zebrafish (Danio rerio) for a dark environment. Brazilian Journal of Medical and Biological Research 32, 1551-1553.

SHIN, J. T. \& FishMAN, M. C. (2002). From zebrafish to human: modular medical models. Annual Review of Genomics and Human Genetics. 3, 311-40.

Snekser, J. L., McRobert, S. P., Murphy, C. E. \& Clotfelter, E. D. (2006). Aggregation behavior in wildtype and transgenic zebrafish. Ethology 112, 181187.

SoKolowsKi, M. B. (2001). Drosophila: genetics meets behaviour. Nature Reviews Genetics 2, 879-890.

Sood, R., English, M.A., Jones, M., Mullikin, J., Wang, D.M., Anderson, M., Wu, D., ChandraseKharappa, S.C., Yu, J., Zhang, J., AND PAUl LiU, P. (2006). Methods for reverse genetic screening in zebrafish by resequencing and TILLING. Methods 39, 220-227.

Spence, R. (2006) The behaviour and ecology of the zebrafish, Danio rerio. PhD Thesis, University of Leicester.

Spence, R., Ashton, R. L. \& Smith, C. (2007b). Adaptive oviposition decisions are mediated by spawning site quality in the zebrafish, Danio rerio. Behaviour 144, 953-966.

Spence, R., Fatema, M. K., Ellis, S., Ahmed, Z. F. \& Smith, C. (2007a). The diet, growth and recruitment of wild zebrafish (Danio rerio) in Bangladesh. Journal of Fish Biology 71, 304-309.

Spence, R., FATEMA, M. K., Reichard, M., HuQ, K. A., Wahab, M. A., Ahmed, Z. F., SMith, C. (2006a). The distribution and habitat preferences of the zebrafish in Bangladesh. Journal of Fish Biology 69, 1435-1448.

SPENCE, R, JoRDAN, W. C, SMITH, C. (2006b). Genetic analysis of male reproductive success in relation to density in the zebrafish, Danio rerio. Frontiers in Zoology 3, 5.

Spence, R. \& Smith, C. (2005). Male territoriality mediates density and sex ratio effects on oviposition in the zebrafish (Danio rerio). Animal Behaviour 69, 13171323.

Spence, R. \& SMith, C. (2006). Mating preference of female zebrafish, Danio rerio, in relation to male dominance. Behavioral Ecology 17, 779-783.

SPENCE, R. \& SMITH, C. (2007). The role of early learning in determining social preferences based on visual cues in the zebrafish, Danio rerio. Ethology 113, 6267.

Spence, R. \& Smith, C. In review. Innate and learned colour preference in the zebrafish, Danio rerio. Ethology. 
SpitzBergen, J. M. \& KenT, M. L. 2003. The state of the art of the zebrafish model for toxicology and toxicologic pathology research - advantages and current limitations Toxicologic Pathology 31S, 62-87.

SteEle, C. W., SCARFE, A. D. \& OWENS, D. W. (1991). The effects of group size on the responsiveness of zebrafish (Brachydanio rerio) to alanine, a chemical attractant Journal of Fish Biology 38, 553-564.

Streisinger, G., Walker, C., Dower, N., Knauber, D. \& Singer, F. (1981). Production of clones of homozygous diploid zebra fish (Brachydanio rerio). Nature 291, 293-296.

Suboski, M. D., Bain, S., Carty, A. E., McQuoid, L. M., Seelen, M. I. \& Seifert, M. (1990). Alarm reaction in acquisition and social transmission of simulatedpredator recognition by zebra danio fish (Brachydanio rerio). Journal of Comparative Psychology, 104, 101-112.

Swain, H. A., Sigstand, C. \& SCAlzO, F. M. (2004). Effects of dizocilpine (MK-801) on circling behaviour, swimming activity, and place preference in zebrafish (Danio rerio). Neurotoxicology and Teratology 26, 725-729.

TAlWAR, P. K. \& Jhingran, A. G. (1991). Inland fishes of India and adjacent countries. Oxford \& I. B. H. Publishing, Calcutta.

TALLing, J. F. \& LEMOALLE, J. (1998). Ecological dynamics of tropical inland waters. Cambridge Univerity Press, Cambridge.

Tocher, D.R., Agaba, M., Hastings, N., Bell, J.G., Dick, J.R., \& Teale, A.J. (2001). Nutritional regulation of hepatocyte fatty acid desaturation and polyunsaturated fatty acid composition in zebrafish (Danio rerio) and tilapia (Oreochromis niloticus).Fish Physiolology and Biochemistry. 24, 309-320

Tropepe, V. \& Sive, H. L. (2003). Can zebrafish be used as a model to study the neurodevelopmental causes of autism? Genes, Brain and Behavior 2, 268-281.

UdVADIA, A. J. \& LinNEY, E. (2003). Windows into development: historic, current, and future perspectives on transgenic zebrafish. Developmental Biology 256, 1-17.

VAN DEN HURK, R. \& LAMBERT, J. G. D. (1983). Ovarian steroid glucuronides function as sex pheromones for male zebrafish, Brachydanio rerio. Canadian Journal of Zoology 61, 2381-2387.

VAN DEN HurK, R., Schoonen, W. G. E. J., van Zoelen, G. A. \& LAMBERT, J. G. D. (1987). The biosynthesis of steroid glucuronides in the testis of the zebrafish, Brachydanio rerio, and their pheromonal function as ovulation inducers. General and Comparative Endocrinology 68, 179-188.

VAscotto, S. G., BeCKHAM, Y. \& Kelly, G. M. (1997). The zebrafish's swim to fame as an experimental model in biology. Biochemistry and Cell Biology 75, 479-485.

VASEMÄGI, A. \& PRIMMER, C. R. (2005). Challenges for identifying functionally important genetic variation: the promise of combining complementary research strategies. Molecular Ecology 14, 3623-3642.

WARGELIUS A, ElLiNGSEN S, FJoSE A (1999). Double-stranded RNA induces specific developmental defects in zebrafish embryos. Biochemical and Biophysical Research Communications 263, 156-161.

Watanabe, M., IWAshita, M., Ishit, M., Kurachi, Y., KaWAKami, A., Kondo, S., AND OKADA, N. (2006) Spot pattern of leopard Danio is caused by mutation in the zebrafish connexin41.8 gene. EMBO Reports 7, 893-897.

Weber, M. \&. DE BeAufort, L. F. (1916). The Fishes of the Indo-Australian Archipelago. E. J. Brill, London.

WESTERFIELD, M. (1995). The zebrafish book; A guide for the laboratory use of zebrafish (Brachydanio rerio).University of Oregon Press, Eugene, OR. 
Williams, F. E., White, D. \& Messer JR., W. S. (2002). A simple spatial alternation task for assessing memory function in zebrafish. Behavioural Processes 58, 125132.

Wisenden, B. D., Vollbrecht, K. A. \& Brown, J. L. (2004). Is there a fish alarm cue? Affirming evidence from a wild study. Animal Behaviour 67, 59-67.

Wootton, R. J. 1998. The ecology of teleost fishes. Dordrecht: Kluwer.

Wright, D., Butlin, R. K. \& CARlborG, Ö. (2006b). Epistatic regulation of behavioural and morphological traits in the zebrafish (Danio rerio). Behavior Genetics 36, 914-922.

Wright, D., NAKAmichi, R., Krause, J. \& Butlin, R. K. (2006a). QTL analysis of behavioural and morphological differentiation between wild and laboratory zebrafish (Danio rerio). Behavior Genetics 36, 271-284.

Wright, D., Rimmer, L. B., Pritchard, V. L., Krause, J. \& Butlin, R. K. (2003). Inter and intra-population variation in shoaling and boldness in the zebrafish (Danio rerio). Naturwissenschaften 90, 374-377.

ZhaO, Z. X., CAO, Y., LI, M., MENG, A. M. (2001). Double-stranded RNA injection produces nonspecific defects in zebrafish. Developmental Biology 229, 215-223.

\section{WEB CITATIONS:}

\section{Fishbase}

www.fishbase.org

The Wellcome Trust Sanger Institute: www.sanger.ac.uk

Zebrafish Information Network (ZFIN), The Zebrafish International Resource Center, University of Oregon: http://zfin.org/ 
Table1. Recognised wild-type zebrafish lines listed by the Zebrafish International $\underline{\text { Resource Center }}$

\begin{tabular}{|c|c|}
\hline Name & Description \\
\hline $\mathrm{AB}$ & $\begin{array}{l}\text { Derived from two lines purchased by George Streisinger from } \\
\text { a pet shop in Albany, Oregon in the late 1970s. The currently } \\
\text { used line *AB was derived from the original AB line in 1991- } \\
1992 \text { by parthenogenesis. }\end{array}$ \\
\hline $\mathrm{AB} /$ Tübingen & $\begin{array}{l}\text { An 'official' line maintained as a cross but the term is also } \\
\text { applied to crosses where the two parental lines are maintained } \\
\text { separately. }\end{array}$ \\
\hline C32 & $\begin{array}{l}\text { Derived from laboratory strains at Oregon. The current } \\
\text { C32bc9 stock is a derivative of Steve Johnson's inbred C32 }\end{array}$ \\
\hline Cologne & $\begin{array}{l}\text { Isolated at the Reugels/Campos-Ortega Lab, University of } \\
\text { Cologne. }\end{array}$ \\
\hline Darjeeling & $\begin{array}{l}\text { Collected in Darjeeling in } 1987 \text { and sent to Monte Westerfield } \\
\text { at Oregon. A much faster swimmer than other wild-type } \\
\text { strains. Used extensively for mapping as it contains many } \\
\text { polymorphic markers. }\end{array}$ \\
\hline Ekkwill (EKW) & $\begin{array}{l}\text { From Ekkwill breeders in Florida and maintained in Grunwald } \\
\text { lab, University of Utah. }\end{array}$ \\
\hline Hong Kong & Stock obtained from a Hong Kong fish dealer. \\
\hline $\mathrm{HK} / \mathrm{AB}$ & Hybrid of Hong Kong and AB wild-type lines \\
\hline HK/Sing & Hybrid of Hong Kong and Singapore wild-type lines. \\
\hline India & Stock obtained from expedition to Darjeeling (wild isolate). \\
\hline Indonesia & Stock obtained from Indonesian fish dealer. \\
\hline Nadia & $\begin{array}{l}\text { Wild-caught about } 40 \text { miles east of Calcutta. The fish were } \\
\text { collected from stagnant ponds and flood plains. Imported in } \\
1999 \text { by a wholesaler in Oregon. Established in the Oregon } \\
\text { laboratory from an initial breeding of about ten individuals. }\end{array}$ \\
\hline Singapore & Stock obtained from Singapore fish dealer. \\
\hline SJA & $\begin{array}{l}\text { sjA is an inbred line of *AB isolated at the Stephen L. } \\
\text { Johnson Lab, Washington University Medical School. Unlike } \\
\text { *AB, which is bred to retain polymorphisms, this subline is } \\
\text { bred to reduce polymorphism and is at least } 85 \%\end{array}$ \\
\hline
\end{tabular}




\begin{tabular}{|ll|}
\hline SJD & monomorphic. \\
Tübingen & Isolated at the Stephen L. Johnson Lab. \\
& $\begin{array}{l}\text { Wild-type short fins. Strain used by Sanger for the zebrafish } \\
\text { sequencing project. It was cleaned up to remove embryonic } \\
\text { lethal mutations from the background before being used for } \\
\text { mutagenesis and sequencing. }\end{array}$ \\
Tübingen long fin & $\begin{array}{l}\text { Homozygous for leo }{ }^{\mathrm{t} 1} \text {, a recessive mutation causing spotting } \\
\text { in adult fish,and lof }{ }^{\mathrm{dt} 2} \text { a dominant homozygous viable } \\
\text { mutation causing long fins. This is not the line used in the } \\
\text { Sanger zebrafish sequencing project. It is genetically different } \\
\text { from TU because it was bred differently and not "cleaned up," } \\
\text { and therefore retains a lot of polymorphisms. }\end{array}$ \\
DIK & $\begin{array}{l}\text { Derived from wild catch in India and used for genome } \\
\text { mapping. }\end{array}$ \\
\hline
\end{tabular}




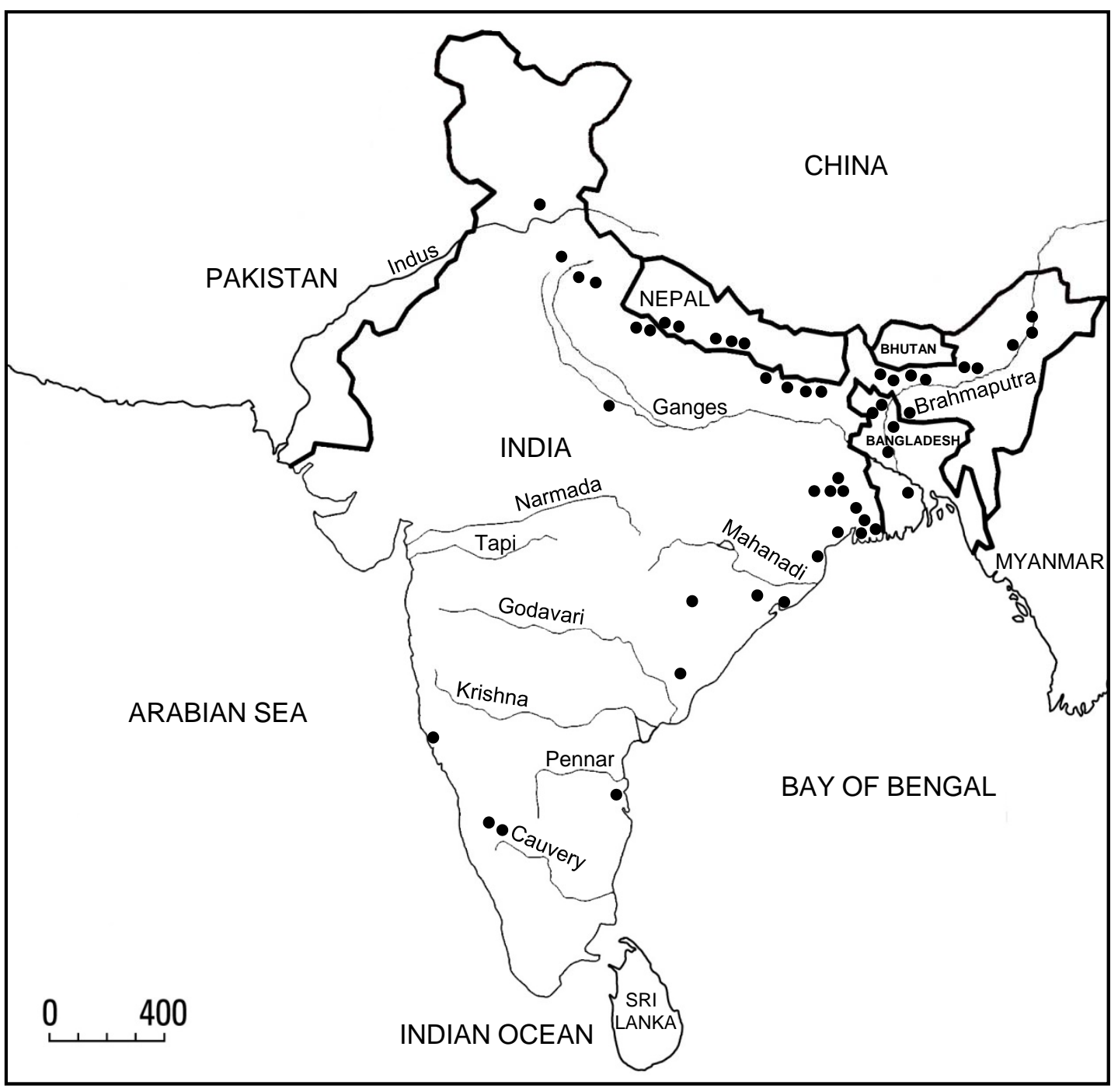

Fig.1. The natural distribution of the zebrafish. Major river systems indicated. Black dots indicate recorded occurrences. 


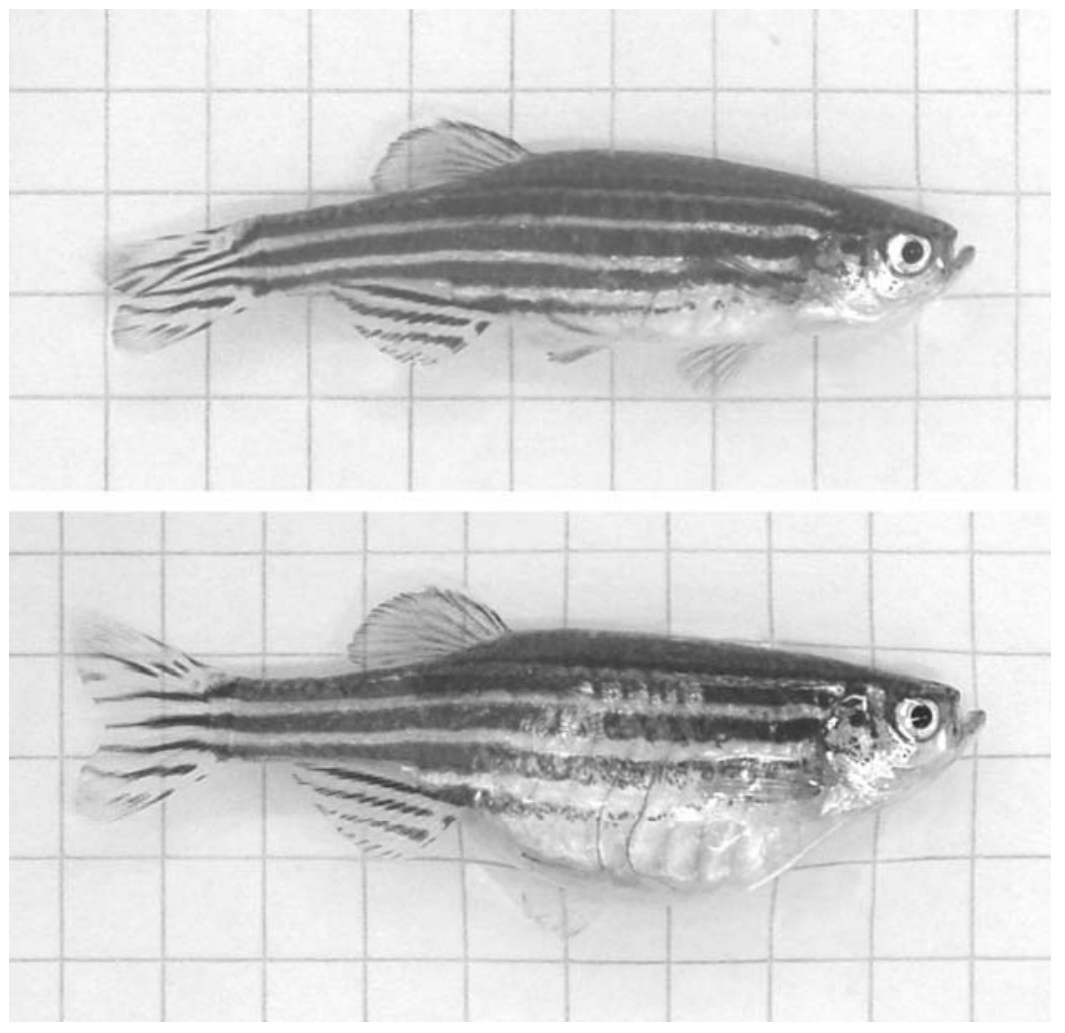

Fig. 2. Female zebrafish a) before and b) after being housed alone for 3 weeks. The belly of the females increased, on average, by $69 \pm 24 \%(n=10)$. 